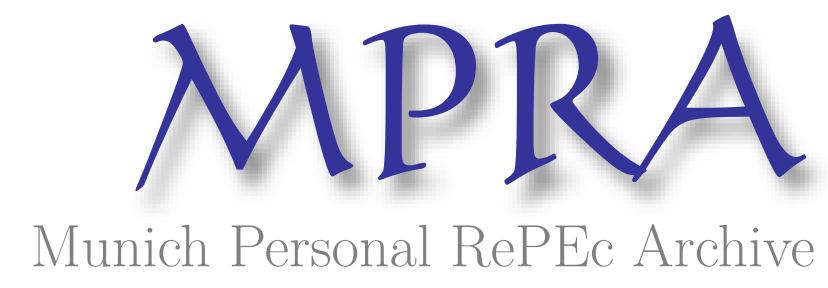

\title{
Non-linear models: applications in economics
}

\author{
Albu, Lucian-Liviu
}

2006

Online at https://mpra.ub.uni-muenchen.de/3100/

MPRA Paper No. 3100, posted 05 May 2007 UTC 


\title{
Non-linear models: applications in economics
}

\author{
Lucian-Liviu Albu \\ (Institute for Economic Forecasting, Bucharest)
}

\begin{abstract}
The study concentrated on demonstrating how non-linear modelling can be useful to investigate the behavioural of dynamic economic systems. Using some adequate non-linear models could be a good way to find more refined solutions to actually unsolved problems or ambiguities in economics. Beginning with a short presentation of the simplest non-linear models, then we are demonstrating how the dynamics of complex systems, as the economic system is, could be explained on the base of some more advanced non-linear models and using specific techniques of simulation. We are considering the non-linear models only as an alternative to the stochastic linear models in economics. The conventional explanations of the behaviour of economic system contradict many times the empirical evidence. We are trying to demonstrate that small modifications in the standard linear form of some economic models make more complex and consequently more realistic the behaviour of system simulated on the base of the new non-linear models. Finally, few applications of non-linear models to the study of inflation-unemployment relationship, potentially useful for further empirical studies, are presented.
\end{abstract}

Key words: non-linear model, continuous time map, strange attractor, fractal dimension, natural unemployment

JEL Classification: C02, C63, E27, E32

\section{Introduction}

Traditionally economists preferred linear models or at least those that can be interpreted as linear ones in the neighbourhood of a solution. In analysis of dynamic processes they used only simple linear differential equations that generate regular and stable cycles. They made distinction between deterministic systems manifesting predictable behaviour and statistic series reflecting random or stochastic behaviour therefore unpredictable. Chaotic behaviour of these series was simple interpreted as being stochastic and in estimating linear models the inconvenient observations were classified as accidental and consequently ignored. However, last time we can see an impressive growth of preoccupation in scientific community to analyse non-linear systems. Approaching of such systems mostly in mathematics and in natural sciences generated fundamentally new concepts and methods. In economics their application is only at the beginning, but however some remarkable results emerged. There are a number of economic fields in which non-linear methods could be useful, such as behaviour of capital market and exchange rate, problems in external debt, economic crises, hyperinflation and banking risk etc. 
Because many times the behaviour of non-linear systems can be investigated only by numerical analysis, the development of non-linear models can be considered as a result of PC time. Theorems are demonstrated numerical or computer-assisted. It was discovered that even simple non-linear models are able to simulate various behaviours and to reflect new properties. So, infinitesimal changes in value of some key-parameters can generate unexpected effects - this was the case even for some simple classic models, considered in the past as being characterized by a clear cyclical behaviour and therefore highly predictable. This generated the concept of so-called deterministic chaos. Numerical simulations permitted to develop new theories or to incorporate classic theories in theories of higher level. Moreover, concepts as equilibrium and stability were revised.

\section{Complex behaviour of the logistic equation}

Logistic equation play an important role in mathematics of chaos development, supplying however as base in developing economic applications. Let's consider variable $Y_{t}$, where $0 \leq \mathrm{Y}_{\mathrm{t}} \leq 1$ and $\mathrm{t}=1,2,3, \ldots$ The discrete dynamic system:

$$
\begin{aligned}
\mathrm{Y}_{\mathrm{t}+1} & =\mathrm{f}\left(\mathrm{Y}_{\mathrm{t}}\right) \\
& =\mu \mathrm{Y}_{\mathrm{t}}\left(1-\mathrm{Y}_{\mathrm{t}}\right)
\end{aligned}
$$

is known in literature as logistic equation.

The following simple dynamic model of the advertising expenditure in a company supplies one example. We assume the following relation between advertising expenditures and level of income: when advertising expenditures, $\mathrm{Y}_{\mathrm{t}}$, increase the level of income, $X_{t}$, firstly rises then, after a maximum, begins to decrease. Also, we consider that advertising expenditures in next period are proportional with income of company obtained in current period:

$\mathrm{X}_{\mathrm{t}}=\lambda \mathrm{Y}_{\mathrm{t}}\left(1-\mathrm{Y}_{\mathrm{t}}\right), \lambda>0$

$\mathrm{Y}_{\mathrm{t}+1}=\gamma \mathrm{X}_{\mathrm{t}}, \gamma>0$

Combining the two equations resulted logistic equation (1), where $\mu=\lambda \gamma$. Simulation of logistic equation model demonstrates dramatic changes in the behaviour of system function of values for parameter $\mu$, as in Figures 1 and 2. It is more complex: if value of parameter $\mu$ increases beyond 3, non-depending on the starting value of $Y_{t}$, cobweb cycles enter a limit-cycle around a fix square. This means that the values fluctuate between two values or equivalent - a stable cycle of two periods emerges. For instance, for $\mu=3.1 Y_{t}$ fluctuates between 0.764566520 and 0.558014125 . Such cycle of two periods, in case of $\mu=3.2$, is shown in Figure 3. If $\mu$ is beyond 3.449 the system enter a region of stability demonstrating a cycle of four periods. For example, if $\mu=3.51$ the values of $\mathrm{Y}_{\mathrm{t}}$ fluctuate between $0.877341821,0.377722156,0.825018932$ and 0.506713055 . Such cycle of four periods, in case of $\mu=3.5$, is shown in Figure 4 . When parameter $\mu$ is 3.544 cycles of eight periods emerge, for $\mu=3.564$ cycles of sixteen periods emerge. Beyond this value the doubling of periods accelerates until $\mu$ becomes equal to 3.57, when the system never returns on a fix point. At this point the system enter 
a chaotic state, as is shown in Figure 5 for value 3.83 . The system is not chaotic for all values of $\mu$ over 3.57. At some points thee-cycle period emerges. For instance, if $\mu=3.836$ the values of $\mathrm{Y}$ tend to $0.151479312,0.493053855$ and 0.958814917 respectively. Infinitesimal changes in parameter $\mu$ generate again doubling of periods to $6,12,24$ etc., finally chaos emerging again. When parameter $\mu$ is 3.7390 five-cycle periods emerge, $\mathrm{Y}_{\mathrm{t}}$ having values $0.934749476,0.228052428,0.658230452,0.841137120$ and 0.499625614 . In case of a value of parameter $\mu$ continuing to increase there will be a region of rapid doubling of periods, finally again emerging a chaotic regime.

(a) $\mu=2.0$

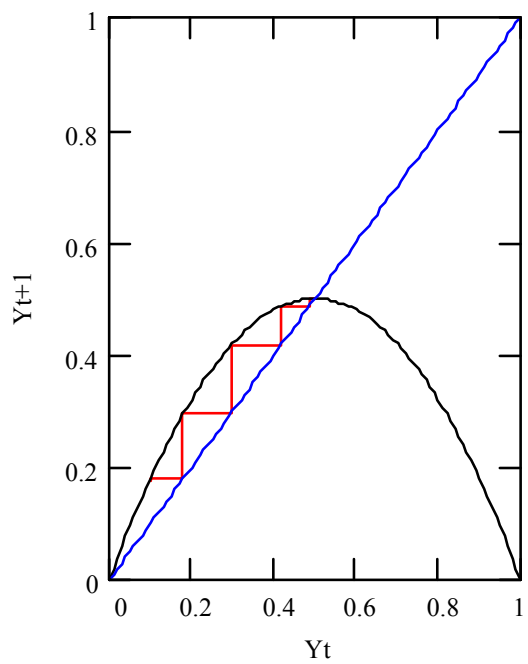

(b) $\mu=2.0$

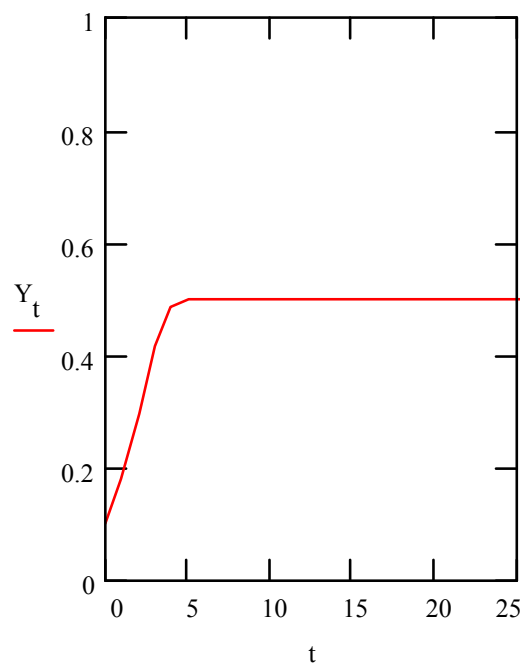

Figure 1.

(a) $\mu=2.8$

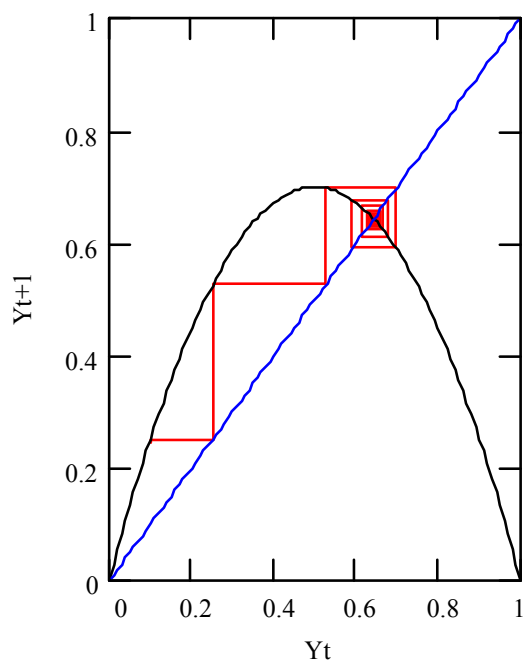

(b) $\mu=2.8$

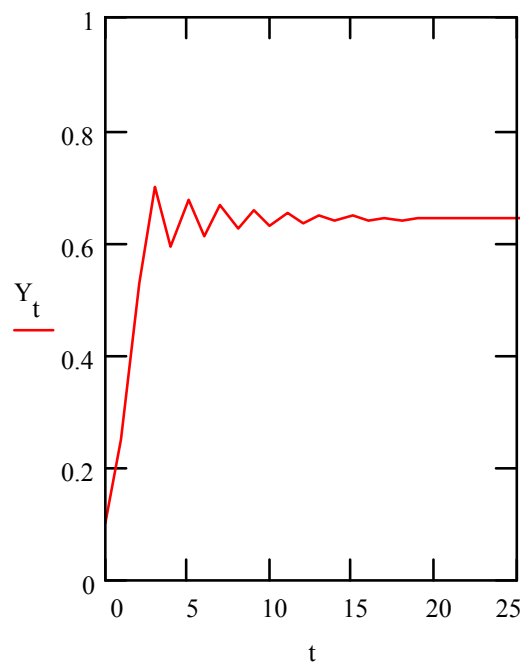

Figure 2. 
(a) $\mu=3.2$

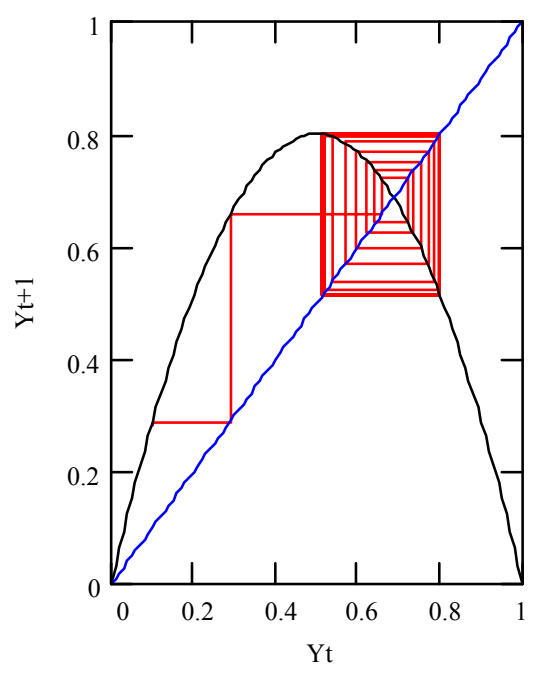

(b) $\mu=3.2$

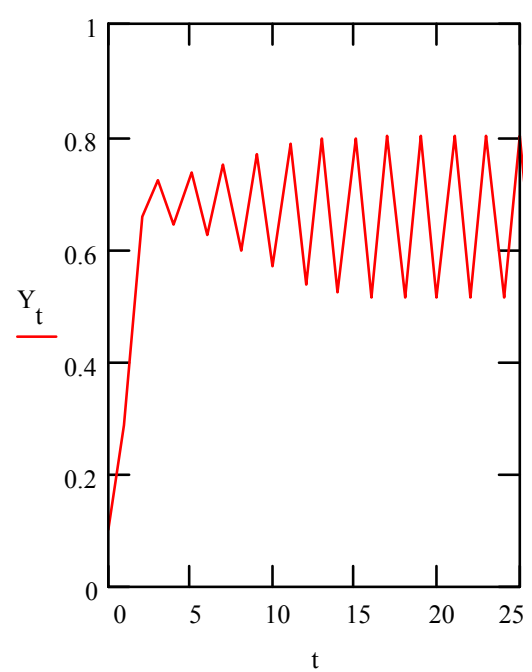

Figure 3.

(a) $\mu=3.5$

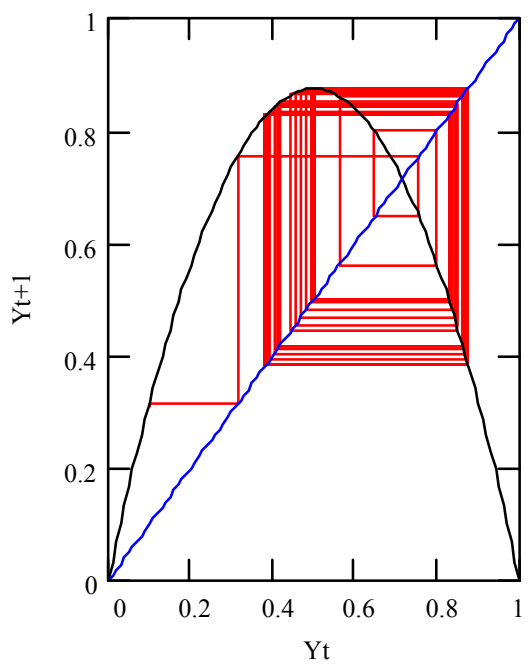

(b) $\mu=3.5$

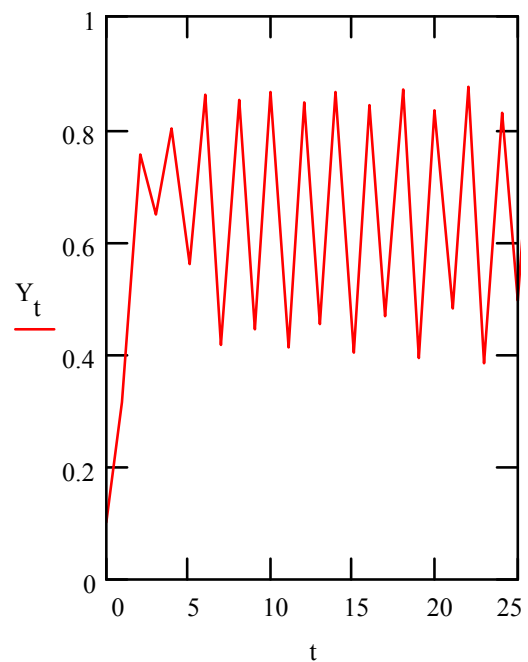

Figure 4. 
(a) $\mu=3.83$

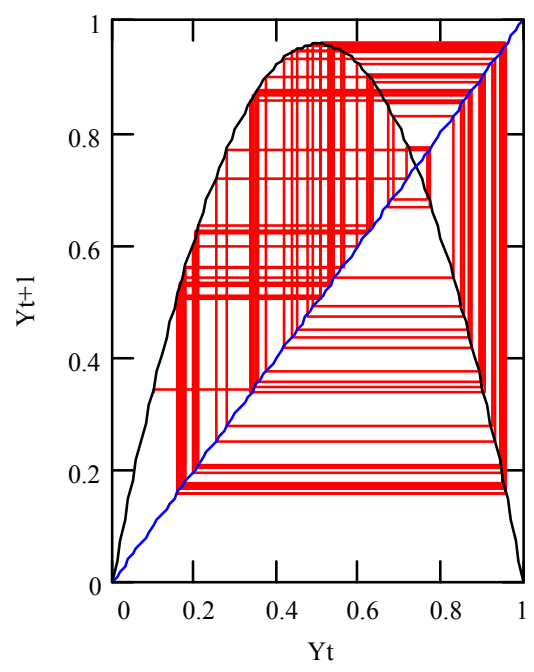

(b) $\mu=3.83$

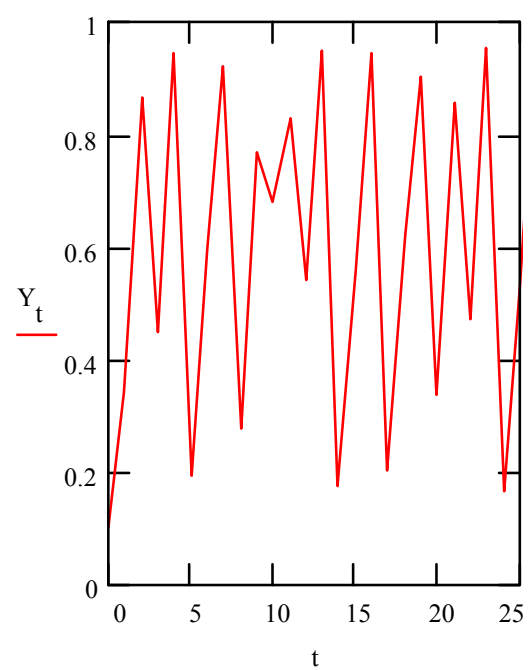

Figure 5.

Information on the behaviour of logistic model for all values of parameter $\mu$ can be presented as a so-called bifurcation diagram presented in Figure 6.

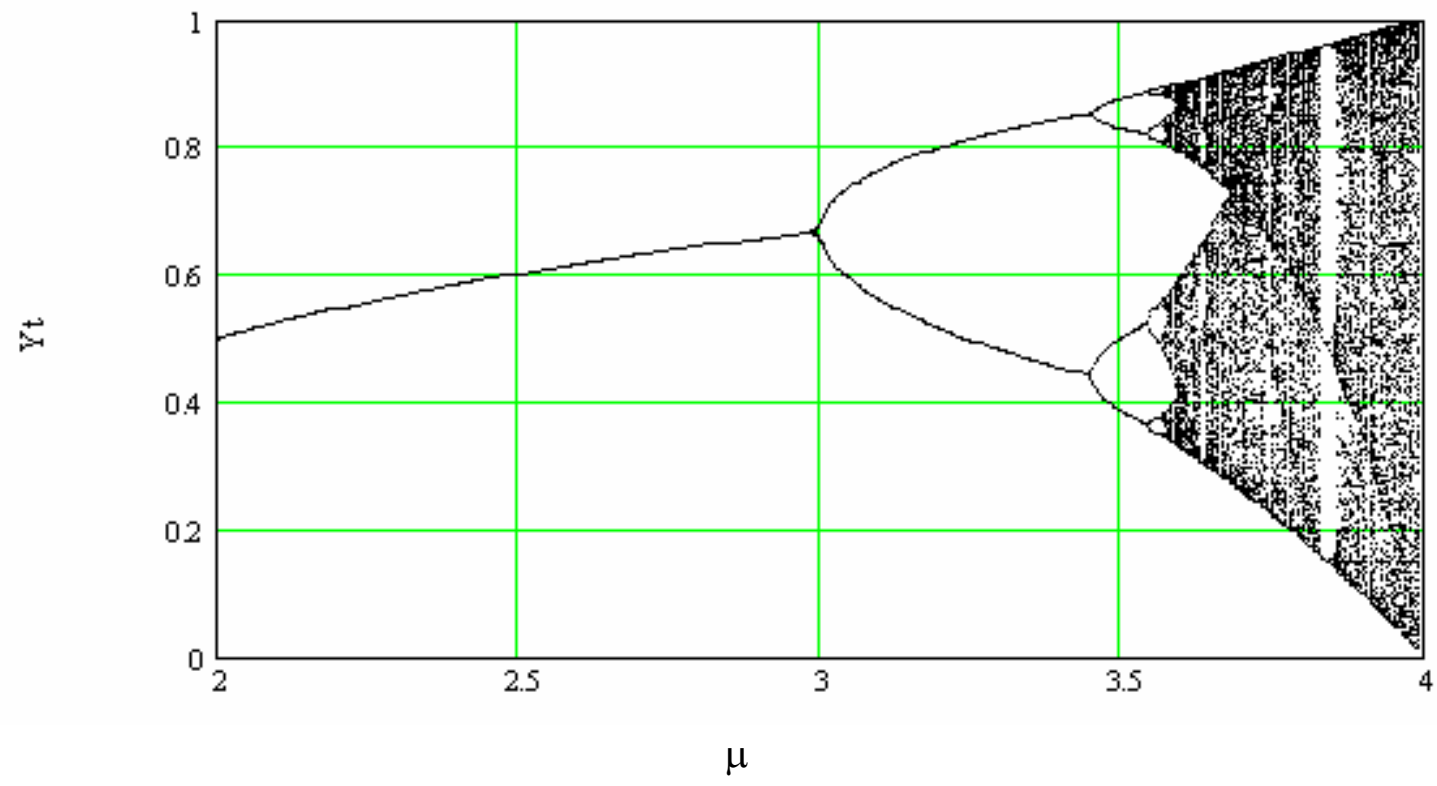

Figure 6.

For parameter $\mu$ between 3.57 and 4.0 on the bifurcation diagram we can see some black bands, corresponding to chaos, separated by windows (so-called order emerged from chaos). In case that we focus on a window using a higher resolution to see within it, the 
picture is identically to integral diagram - this characteristic of logistic system is called self-similarity, as it is suggested in Figure 7.

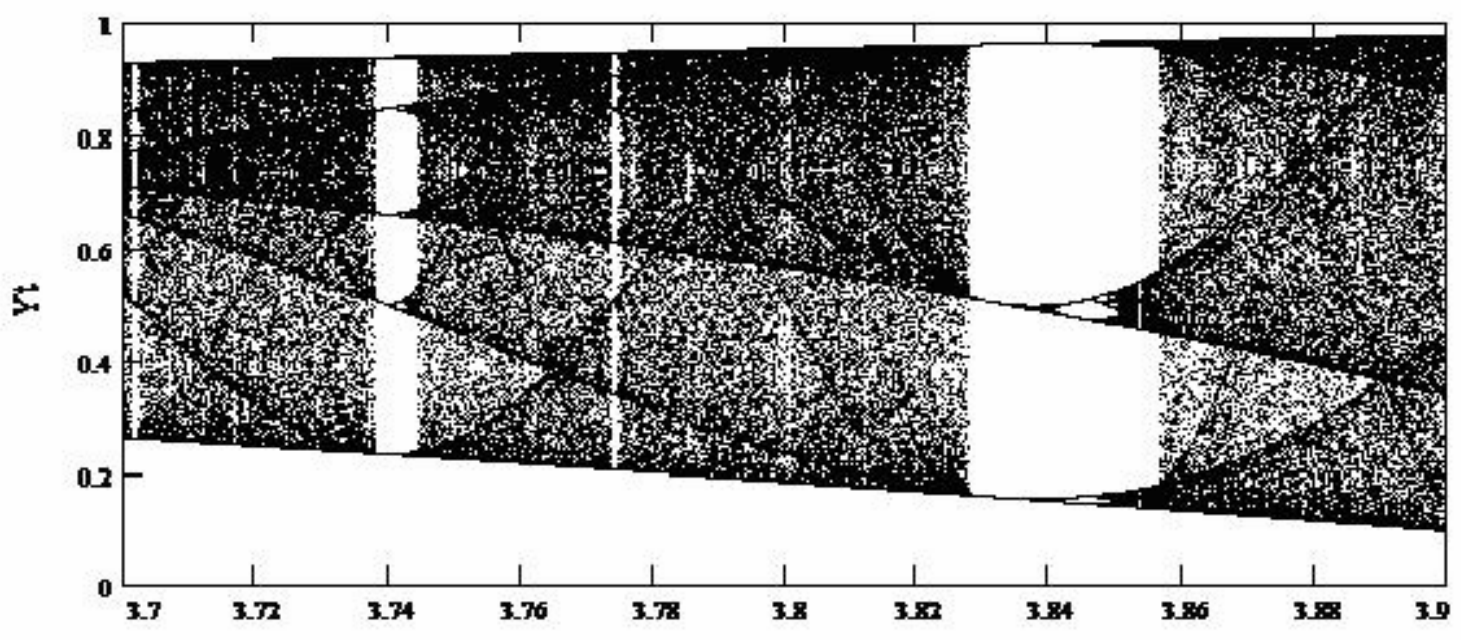

$\mu$

Figure 7.

Other characteristic of non-linear models is the sensitivity to initial conditions, as it is shown in Figure 8, where we used two initial values for Y, 0.2 and respectively 0.201 (after only 15 iterations the two trajectories of $\mathrm{Y}$ are already divergent). This characteristic suggests a high degree of incertitude to forecast on long run in case of a dynamic system fundamentally non-linear.

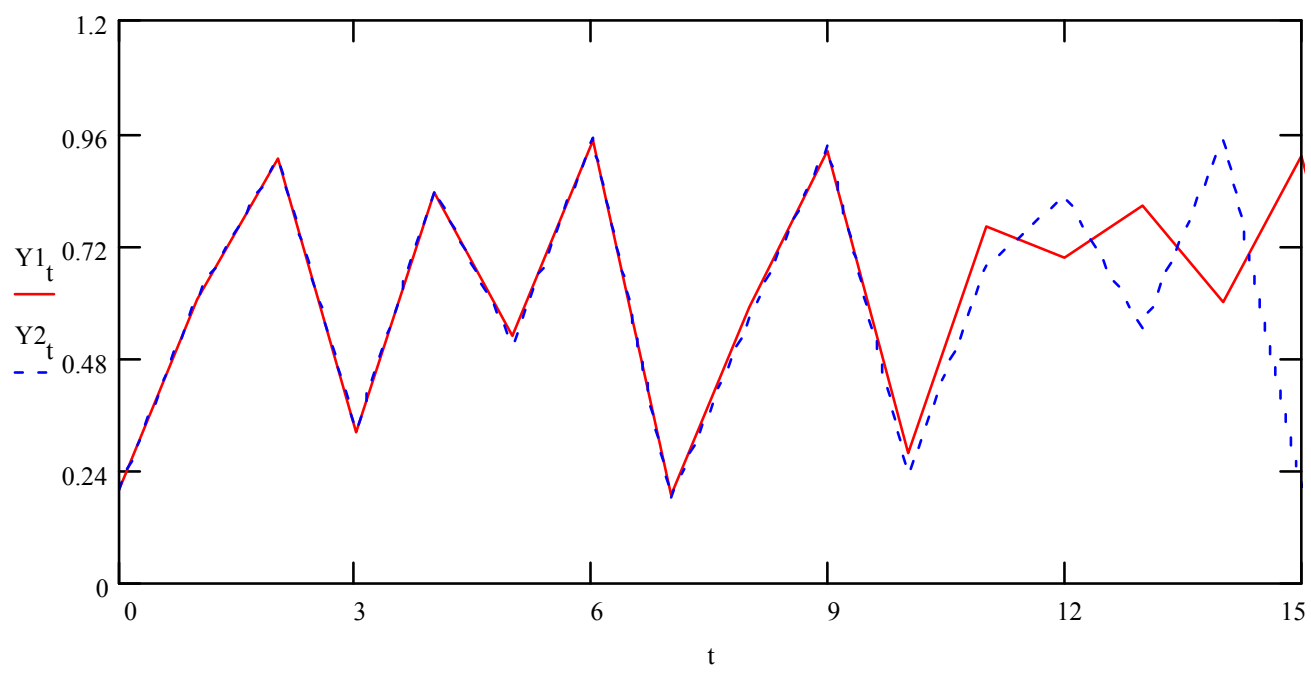

Figure 8. 


\section{One dimensional discrete maps}

Logistic equation is only one example of the so-called one-dimensional discrete time. Other examples are the following:

$Y_{t+1}=Y_{t} \exp \left(\mu\left(1-Y_{t}\right)\right), \mu>0$

$\mathrm{Y}_{\mathrm{t}+1}=\mathrm{Y}_{\mathrm{t}}+\mu \mathrm{Y}_{\mathrm{t}}\left(\mathrm{Y}_{\mathrm{t}}^{2}-1\right)$

$\mathrm{Y}_{\mathrm{t}+1}=\mu \sin \left(\mathrm{Y}_{\mathrm{t}}\right)$

They are called exponential logistic, cubic and trigonometric. Their properties take on supplementary significance when the extension is made to the whole one-dimensional space.

In previous section it is shown that for $0<\mu<1$ the origin is a stable fixed point, but for $1<\mu<3$ there is a stable fixed point equal to $1-1 / \mu$. Such points were found in an analytical manner and numerical computation permitted to discover that when parameter $\mu$ increases beyond of value 3 the process enter in a cyclical phase in which emerges a doubling of the period until the phase of deterministic chaos occurs. Further, when $\mu$ continues to increase new and new additional "windows" of doubling the period occur that at their turn conduct to new chaotic zones. Identification of all values of $\mu$ for which doubling of the period is registered proves to be very difficult without of a powerful computer. Such research permitted to Feigenbaum (1978) to discover a more general property than initially is not even thought by simple numeric simulation. The result was the discover of an universal constant that today is called Feigenbaum constant. To demonstrate the universal constant of Feigenbaum we define $\mu_{n}$ as a point of doubling period. Let us consider the following rate:

$\delta=\left(\mu_{\mathrm{n}}-\mu_{\mathrm{n}-1}\right) /\left(\mu_{\mathrm{n}+1}-\mu_{\mathrm{n}}\right)$

expressing the ratio between previous change of parameter necessary to obtain doubling of the period and current change necessary for doubling of the cyclical period. Feigenbaum discovered that independently from $\mathrm{n}$ value the ratio takes the same value, namely approximately 4.6692 . Also, he demonstrated that this constant occurs in case of numerous one-dimensional maps. The number 4.6692, known today as Feigenbaum number, is proved to be a universal constant, as number $\pi$ or number $\mathrm{c}$ (the light speed in vide). One direct implication of above relation is that when $\mu_{\mathrm{n}-1}$ and $\mu_{\mathrm{n}}$ are known then it is possible to compute $\mu_{\mathrm{n}+1}$. For instance, as in previous section the first two points for which a doubling period of cycles occurs are $\mu_{\mathrm{n}-1}=3$ and respectively $\mu_{\mathrm{n}}=3.449$. By substitution we can obtain:

$\mu_{\mathrm{n}+1}=\mu_{\mathrm{n}}+\left(\mu_{\mathrm{n}}-\mu_{\mathrm{n}-1}\right) / \delta \cong 3.56$

As we showed the values of $\mu$ in chaos region, $3.57<\mu<4$, generate cycles of odd range. Identification of a cycle of three-period become relevant for understanding of economic models coming from the Sarkovskii's demonstration, who showed that since a model proves to have a three-period cycle then it also could generate cycles of all 
possible ranges (see Guckenheimer and Holmes, 1983). This important result it was already demonstrated in case of logistic model. Li and Yorke (1975), using the Sarkovskii's result, demonstrated that in case that a map has a three-cycle then it presents periodic and irregular behaviour. All mappings (simulations) satisfying this propriety generate chaos in Li-Yorke sense. As a synthetic expression could be: period three implies chaos. Let's consider a dynamic series given by $\mathrm{Y}_{\mathrm{t}}$. If one of the following conditions are satisfied

$\mathrm{Y}_{\mathrm{t}+3}<\mathrm{Y}_{\mathrm{t}}<\mathrm{Y}_{\mathrm{t}+1}<\mathrm{Y}_{\mathrm{t}+2}$

$\mathrm{Y}_{\mathrm{t}+3}>\mathrm{Y}_{\mathrm{t}}>\mathrm{Y}_{\mathrm{t}+1}>\mathrm{Y}_{\mathrm{t}+2}$

then two distinct time trajectories of $\mathrm{Y}_{\mathrm{t}}$, although can be by chance very closed initially, in the future they will diverge significantly. One implication of the Sarkovskii, Li and Yorke's results is that order can exist within chaotic region. Referring to Figures 6 and 7, for values of $\mu$ within chaotic region, $3.57<\mu<4$.0, however there exist windows (subregions) in which stable cycles exist. Such results suggest that, for instance, regarding the prices, an economy operating within an order region will present stable and smooth cycles. Within this region the market principles determine price. However, if the fundamental parameters of the model change then economy could be pushed in a chaotic region characterised by ample and frequent movements of prices.

\section{Higher order discrete maps}

A property of one-dimensional discrete maps is that they tend to a so-called saw-tooth trajectory. This is usually unrealistic for almost economic variables since it suggests that an increase in a particular economic aggregate is immediately followed by a decrease. Moreover, one-dimensional models represent only a special case of more general equilibrium economic systems. That is why it is useful to investigate the implications of non-linearity in higher dimensional systems. However, we must note that although there exist a number of theorems to help identify the structure of attractors for one-dimensional discrete maps, there is less help for n-dimensional systems. One of the most known multivariate discrete maps is that named as the Henon attractor, which is based on the following bivariate non-linear discrete set of equations:

$\mathrm{X}_{\mathrm{t}+1}=1-\gamma \mathrm{X}_{\mathrm{t}}^{2}+\mathrm{Y}_{\mathrm{t}}$

$\mathrm{Y}_{\mathrm{t}+1}=\beta \mathrm{X}_{\mathrm{t}}$

where $\gamma$ and $\beta$ are positive parameters. In Figure 9 there are presented the properties of the Henon map for $\gamma=1.4$ and $\beta=0.3$. A time series plot of $X_{t}$ in Figure 9a shows that the series tends to behave in an aperiodic manner and the phase diagram in Figure $9 \mathrm{~b}$ demonstrates the emergence of a "bananas-shaped" object. This is just the Henon attractor, meaning, for given starting values of $X_{t}$ and $Y_{t}$, the region to which the processes simulated by model converge very quickly. The observed chaos in the map is coming from the property that the distance between any two successive points is uncertain. This attractor also displays a self-similarity feature that is highlighted in Figure $10 \mathrm{a}$, where part of the Henon attractor is magnified. The graphical representation shows 
three bands consisting of a single line, a double line and a quadruple line. By zooming in on the quadruple line band in Figure 10b, the same picture is repeated but at a finer scale. This is just the order in the Henon map.

(a)

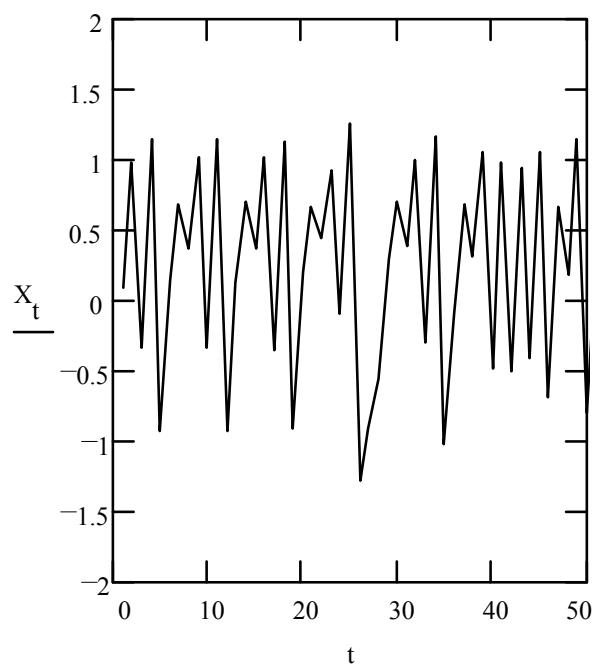

(b)

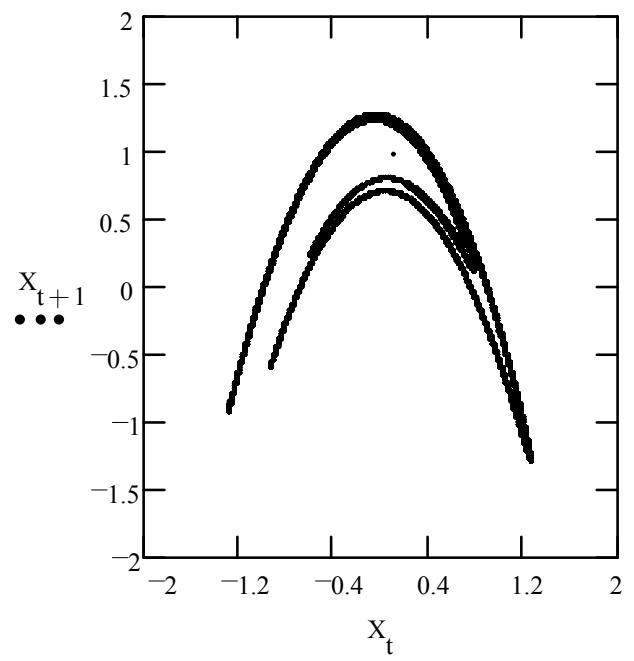

Figure 9.

(a)

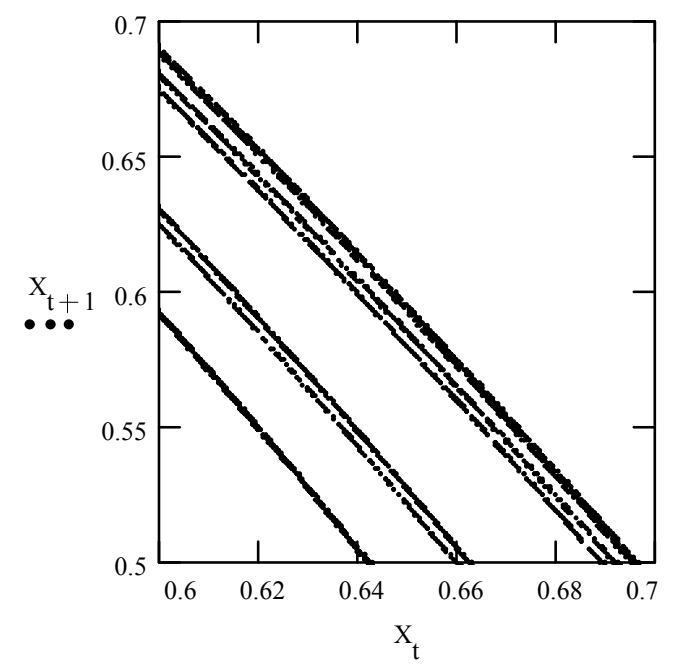

(b)

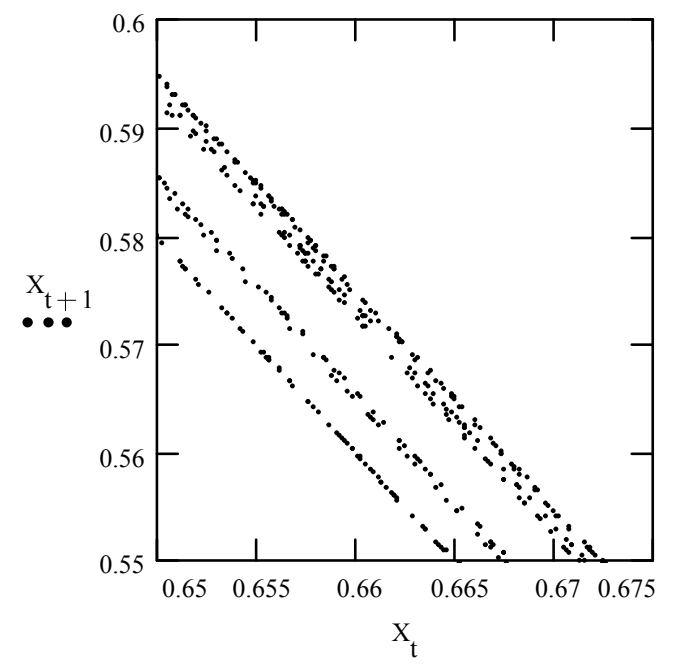

Figure 10. 
As prototype of a multivariate discrete non-linear model in economics is usually considered the following discrete time version of the Kaldor business-cycle model (see Lorentz, 1989, p.130): linear discrete set of equations:

$\mathrm{Y}_{\mathrm{t}+1}-\mathrm{Y}_{\mathrm{t}}=\alpha\left[\mathrm{I}_{\mathrm{t}}\left(\mathrm{Y}_{\mathrm{t}}, \mathrm{K}_{\mathrm{t}}\right)-\mathrm{S}_{\mathrm{t}}\left(\mathrm{Y}_{\mathrm{t}}\right)\right]$

$\mathrm{K}_{\mathrm{t}+1}-\mathrm{K}_{\mathrm{t}}=\mathrm{I}_{\mathrm{t}}\left(\mathrm{Y}_{\mathrm{t}}, \mathrm{K}_{\mathrm{t}}\right)-\delta \mathrm{K}_{\mathrm{t}}$

$\mathrm{I}_{\mathrm{t}}\left(\mathrm{Y}_{\mathrm{t}}, \mathrm{K}_{\mathrm{t}}\right)=\mathrm{c} 2^{-1 /[(\mathrm{dYt}+\varepsilon) 2]}+\mathrm{e} \mathrm{Y}_{\mathrm{t}}+\mathrm{a}\left(\mathrm{f} / \mathrm{K}_{\mathrm{t}}\right)^{\mathrm{g}}$

$\mathrm{S}_{\mathrm{t}}=\mathrm{s} \mathrm{Y}_{\mathrm{t}}$

where $Y_{t}$ is output, $K_{t}$ - the stock of capital, $I_{t}$ - gross investment, $S_{t}$ - savings, and $\alpha=$ $20.0, \delta=0.05$, as the depreciation rate on capital, $\mathrm{c}=20.0, \mathrm{~d}=0.01, \varepsilon=0.00001, \mathrm{e}=$ $0.05, \mathrm{a}=5.0, \mathrm{f}=280.0, \mathrm{~g}=4.5$ and $\mathrm{s}=0.21$, are parameters. Equation (13) shows that changes in output occur when there is a gap between savings and investment. Equation (14) shows that net additions to the stock of capital occur when gross investment exceeds replacement investment, $\delta \mathrm{K}_{\mathrm{t}}$. The non-linearities are implemented into the model by the sigmoidal investment function reflected by relation (15) and equation (16) represents a simple linear savings function. The dynamics of the model are governed primarily by the parameter $\alpha$. So, the model displays a unique stationary point for small values of $\alpha$, whereas for larger values there is a closed orbit. In case of very large values of $\alpha$, there is no relationship between $\mathrm{Y}$ and $\mathrm{K}$. This chaotic pattern is highlighted in Figure 11a where a simulation of time series plot of $Y_{t}$ is shown. A graphical representation of this attractor is presented in Figures 11b, 11c, and 11d, in case of considering the $Y_{t}-K_{t}$ plane, the $Y_{t+1}$ - $\mathrm{Y}_{\mathrm{t}}$ plane and the $\mathrm{K}_{\mathrm{t}+1}-\mathrm{K}_{\mathrm{t}}$ plane respectively.

A multivariate analogue of the Li-Yorke Theorem was given by Marotto (1978). This was facilitated by introduction of the concept of a snap-back repeller. So, it was demonstrated that if a process has a snap-back repeller then it is chaotic. A snap-back repeller arises when for small deviations from a fixed point the trajectory is repelled, while for large deviations the process jumps on to the fixed point. In order to identify a snap-back repeller it is necessary to derive the eigenvalues of the system and show that for values of the state variables close to the fixed point the eigenvalues lie outside the unit circle, whereas for values of the state variables that are not close to the fixed point the eigenvalues lie within the unit circle. However, from practical viewpoint snap-back repellers in general can only be identified using simulation procedures. As an example, we mention here that in a non-linear business-cycle model (a model relatively similar to the Kaldor business-cycle model), Hermann (1985) found, by using a certain set of parameters, that a snap-back repeller exists. 
(a)

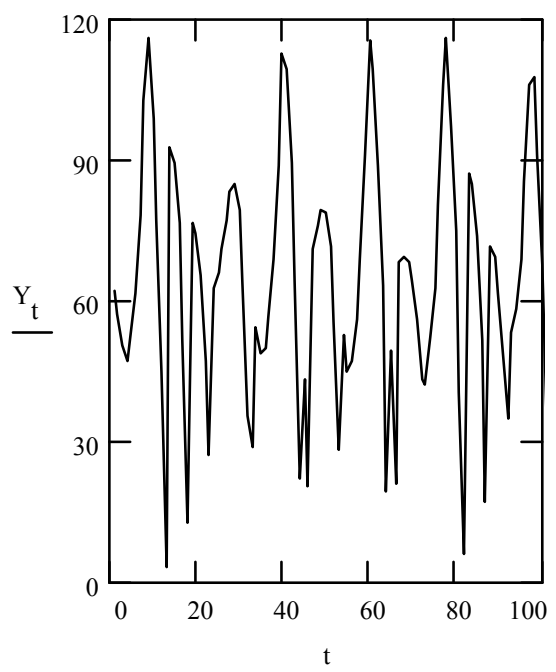

(c)

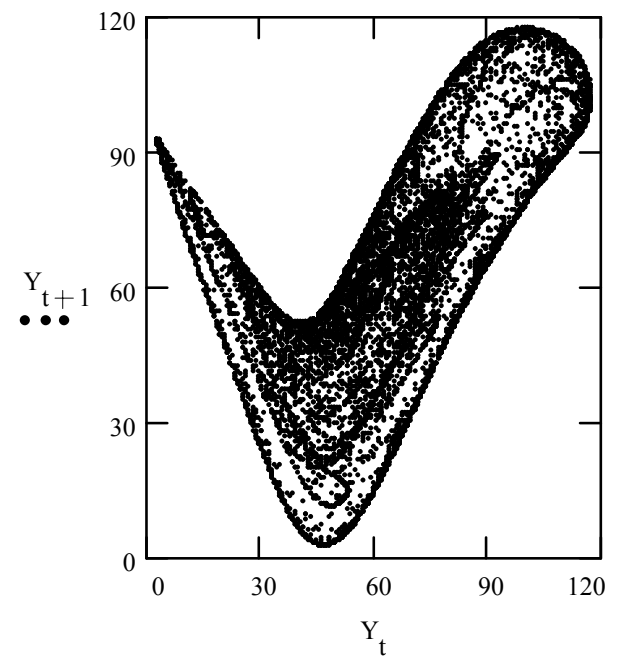

(b)

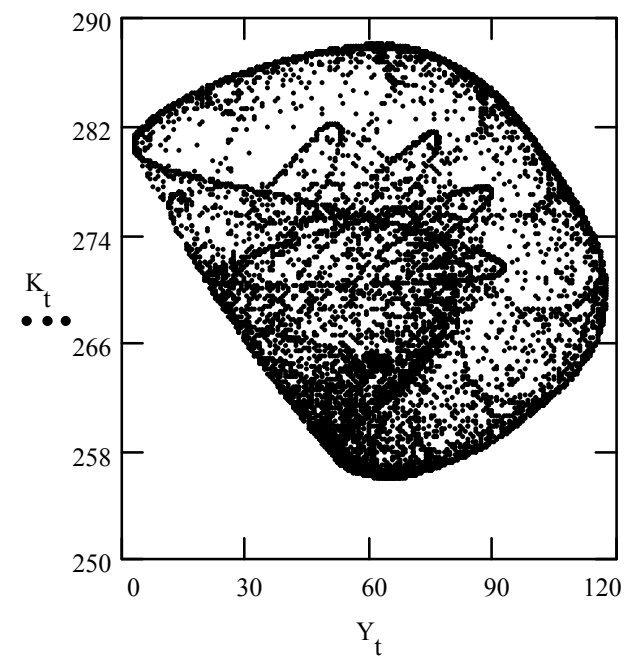

(d)

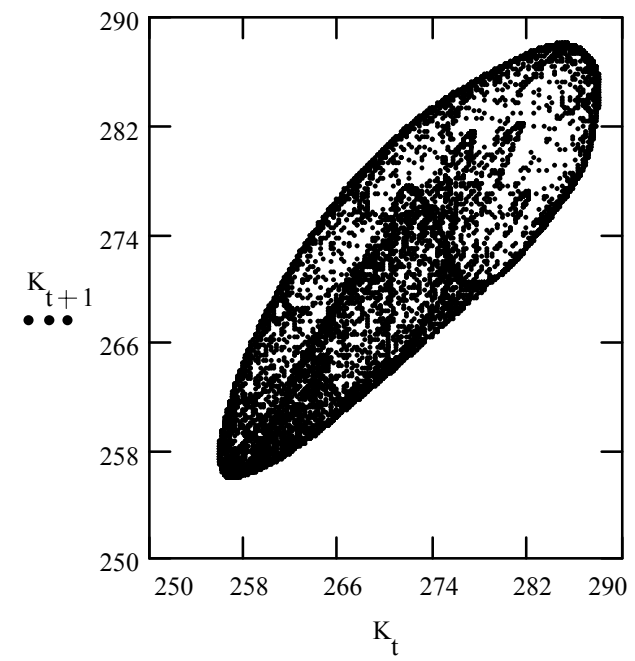

Figure 11.

\section{Continuous time maps}

In last section we concentrated on showing how non-linearities in one-dimensional or higher-order discrete economic models can generate chaotic behaviour. Particularly, in case of discrete time chaotic motion was identified when the process jumps irregularly over the attractor, but economic models are also constructed in continuous time. Due to their properties, in case of continuous time models, chaos cannot be defined in terms of discrete jumps over an attractor, as is the case in discrete models. Rather, the trajectory path over the attractor needs to be smooth and this has led to the definition of so-called 
strange attractors (Ruelle and Takens, 1971). Strange attractor was initially conceived in terms of continuous time systems, but last time they tend to be identified in case of discrete time systems as well. Generally, to be "strange" an attractor needs to satisfy the following properties (Ruelle, 1979): 1) all trajectories remain within a region; 2) sensitive dependence on initial conditions; and 3) the attractor cannot be split into two or more pieces. Finally, if a system has a strange attractor, then the system is called chaotic. For an attractor to be identified as strange, the dimension of a continuous time system needs to be at least equal to three. The reasons for this are as follows: - in a one-dimensional continuous time model the trajectory of the state variable is smooth and thus the irregular jumps already identified in the one-dimensional discrete maps are prelucted in the onedimensional continuous time maps; - two-dimensional continuous time systems also cannot exhibit chaotic behaviour since the trajectory cannot intersect itself. Only in case of three-dimensional or higher-order continuous time systems a smooth trajectory can behave in a supposedly irregular pattern over the attractor without intersecting another trajectory.

The Lorenz attractor is based on the following continuous time non-linear trivariate system of equations (Lorenz, 1963):

$\mathrm{dX} / \mathrm{dt}=-\alpha(\mathrm{X}-\mathrm{Y})$

$\mathrm{dY} / \mathrm{dt}=\beta \mathrm{X}-\mathrm{Y}-\mathrm{XZ}$

$\mathrm{dZ} / \mathrm{dt}=-\gamma \mathrm{Z}+\mathrm{XY} \quad \alpha, \beta, \gamma>0$

The properties of this attractor could be highlighted by using the following parameter values: $\alpha=10.0, \beta=60.0$ and $\gamma=8 / 3$. Among them, the key parameter is $\beta$ (see Gilmore, 1981). Also, the key feature of the attractor is the "butterfly" shape, associated with each wing of the attractor being an unstable fixed point. The trajectory over the attractor is as follows: if the trajectory starts on the left wing there is an outward clock wise spiralling motion away from the fixed point; the trajectory eventually traverses to a position near the centre of the right wing where it begins spiralling outwards in an anticlockwise direction; when the trajectory approaches the outer boundary of the wing it traverses back to a point near the centre of the left wing and the process is repeated.

The Rossler attractor is also a strange attractor. This attractor is based on the following continuous time trivariate system of equations (Rossler, 1976):

$d X / d t=-(Y+Z)$

$\mathrm{dY} / \mathrm{dt}=\mathrm{X}+\alpha \mathrm{Y}$

$\mathrm{dZ} / \mathrm{dt}=-\beta-\gamma \mathrm{Z}+\mathrm{XZ} \quad \alpha, \beta, \gamma>0$

The amazing feature of this model is that chaotic behaviour is generated from a model with an even similar non-linear structure than the Lorenz system of equations. The key parameter of the Rossler model is $\gamma$. This parameter plays the same role as the parameter $\mu$ in the logistic model since it determines the critical points where period doubling occur as well as the point where chaos emerges. This period doubling effect can be viewed by simulating the model for various values of $\gamma$ with $\alpha=\beta=0.2$. Transition from a twoperiod cycle to a four-period cycle and then to an eight-period cycle can be highlighted in case of changes in $\gamma$ from value 2.4 to value 3.5 and respectively to value 4.0. Further, the 
period doubling sequence continues until the trajectory becomes chaotic; that is, the attractor becomes strange. The structure of the Rossler strange attractor is shown in Figure 12. The three two-dimensional plots in Figures 12a, 12b, and 12c show that the attractor looks like a funnel with the width increasing as $\gamma$ increases. The corresponding time series are depicted in Figure 13. Also, a three-dimensional view of the attractor is given in Figure 14. A feature of the attractor is that there is just one fixed point, which contrasts with the Lorenz attractor where there were two fixed points (placed on the two wings of butterfly). In fact, the Rossler attractor can be considered as a special case of the Lorenz attractor where the trajectory is restricted to just one of the wings of the Lorenz attractor.

(a)

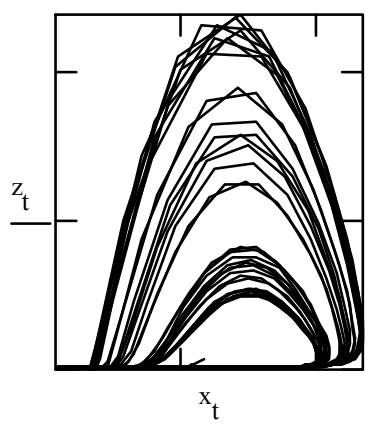

(a)

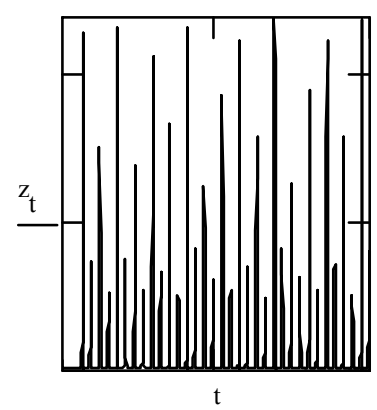

(b)

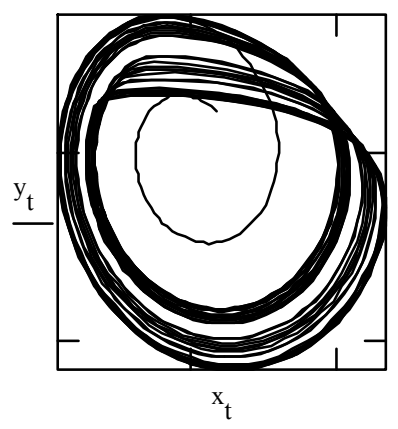

Figure 12.

(b)

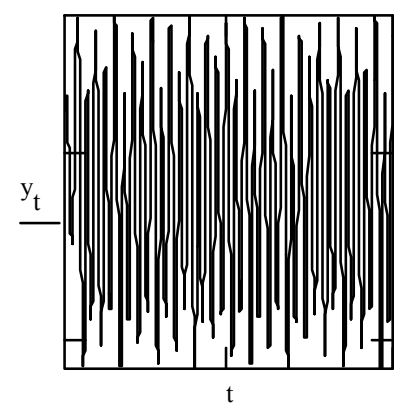

(c)

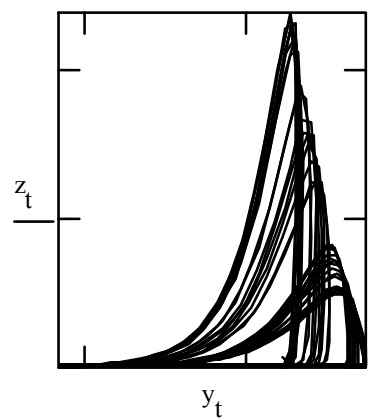

Figure 13. 


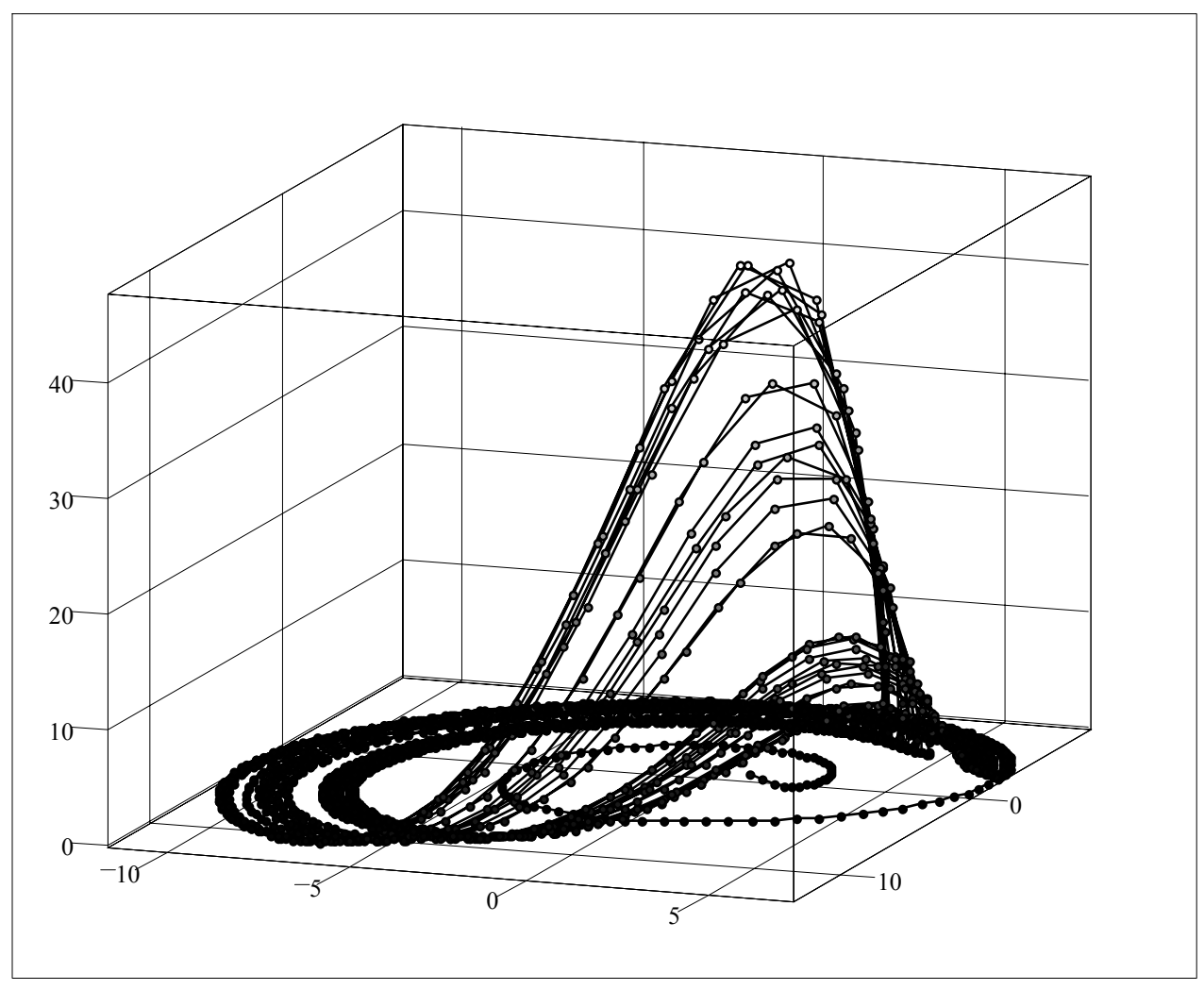

$\mathrm{x}, \mathrm{y}, \mathrm{z}$

Figure 14.

The models included in this section are considered as systems of non-linear first-order differential equations. Also, higher-order differential equations were investigated. Among these the so-called forced oscillators are included. For example, consider the following univariate second-order non-linear differential equation:

$\mathrm{d}^{2} \mathrm{Y} / \mathrm{dt}^{2}+\mathrm{f}(\mathrm{Y}) \mathrm{dY} / \mathrm{dt}+\mathrm{g}(\mathrm{Y})=0$

where $f(Y)$ and $g(Y)$ represent functions. However, the equation (23) is a univariate model when viewed in terms of $Y$, it is actually a two-dimensional system since its properties can be investigated in terms of $\mathrm{Y}$ and $\mathrm{dY} / \mathrm{dt}$. This can be explicitly expressed as a system of two non-linear first-order differential equations as follows:

$\mathrm{dX} / \mathrm{dt}+\mathrm{f}(\mathrm{Y}) \mathrm{X}+\mathrm{g}(\mathrm{Y})=0$

$\mathrm{dY} / \mathrm{dt}=\mathrm{X}$

Although the class of models given by (24) and (25) can generate a wide range of dynamic behaviour, it cannot generate chaotic behaviour since it is a continuous time system with a dimension less than three. In order to increase the dimension of this system is to include time explicitly as follows: 
$d Y^{2} / d t^{2}+f(Y) d Y / d t+g(Y)=h(t)$

where $\mathrm{h}(\mathrm{t})$ is a general function. The last equation is known as a forced oscillator where the forcing term is given by the function $\mathrm{h}(\mathrm{t})$. It is a three-dimensional system and it can also generate chaotic trajectories (for more discussion on forced oscillators, see Guckenheimer and Holmes, 1983, and for economic examples of theses models see Lorenz, 1989).

\section{Applications to investigate inflation-unemployment relationship}

A first step to investigate the inflation-unemployment relationship in case of considering a continuous-time dynamical system is to use the so-called potential function technique in order to obtain some specific spatial representations. Following some old preoccupations (Dăianu and Albu, 1996; Albu, 1998 and 2001), we present only few conclusions based on an empirical analysis of the inflation-unemployment relationship evolution in European area after 1970. Empirical studies demonstrate, on the background of business cycles, some major changes of trends in Western countries during last three decades. Among these it can be noted an impressive decrease in inflation followed by a continuing growth of unemployment and general diminution of the yearly growth rate of production (GDP). An important conclusion is that a smaller volume in 3D map (estimated by including the variation of the three macroeconomic indicators) represents a greater economic stability and consequently less strain in economic system. As example, in Figure 15 it is shown a graphical representation of the evolution during last three decades (1970-2000) in the three-dimensional space (unemployment rate, u\% - annual growth rate, $\mathrm{y} \%$ - inflation, $\pi \%$ ), including ten EU countries (Belgium, Denmark, England, France, Germany, Italy, Ireland, Holland, Portugal, and Spain). Evolution was from a period in which high inflation predominated toward one in which unemployment plays now this role. This evolution could mean that on the unemployment-side occurred a relaxation, higher levels of unemployment being viewed as normal but is not the case for the inflation level. A deeper analysis shows the possibility of some existing persistent trends and long-run attractors. There are evidences demonstrating that the long-run trends in Central and Eastern European countries seem similar to those registered in Western countries. The evolution in Eastern countries in transition period represented only a stage within a long-run wave on the general economic development scale. Also, when the income level per capita rises to a very high level, it was demonstrated a specific evolution process in Western countries, namely that to higher natural rate of unemployment and to a period in which unemployment become more autonomous relating to the dynamics of GDP. Important for the Eastern countries, is that, in actual period of the "new economy" revolution, the converging process do not suppose necessarily a repetition of the Western evolution coming from the " $60 \mathrm{~s}$ and its achieving period could be substantially reduced. In Figure 16 it is shown a 3D representation of the evolution in Romania during last fifteen years (1990-2005).

A simple model of the inflation-unemployment relationship can be also derived from a potential function. Coming from some old papers (Albu, 1995; Daianu and Albu, 1996) 
we apply a simple model that can give us a measure of the stability-degree of inflationunemployment relationship. Let note $\mathrm{S}$ being the sum of unemployment and inflation (in a way very similar to that of Okun's interpretation):

$\mathrm{S}=\mathrm{u}+\mathrm{p}$

where $\mathrm{u}$ is unemployment rate and $\mathrm{p}$ is inflation rate, and let note $\mathrm{P}$ their product:

$\mathrm{P}=\mathrm{u} \cdot \mathrm{p}$

We write the shares of $\mathrm{u}$ and respectively $\mathrm{p}$ in $\mathrm{S}$ by $\mathrm{x} 1$ and respectively $\mathrm{x} 2$ as follows:

$\mathrm{x} 1=\mathrm{u} / \mathrm{S}$ and $\mathrm{x} 2=\mathrm{p} / \mathrm{S}$

and their product as:

$\mathrm{PP}=(\mathrm{u} / \mathrm{S}) \cdot(\mathrm{p} / \mathrm{S})$

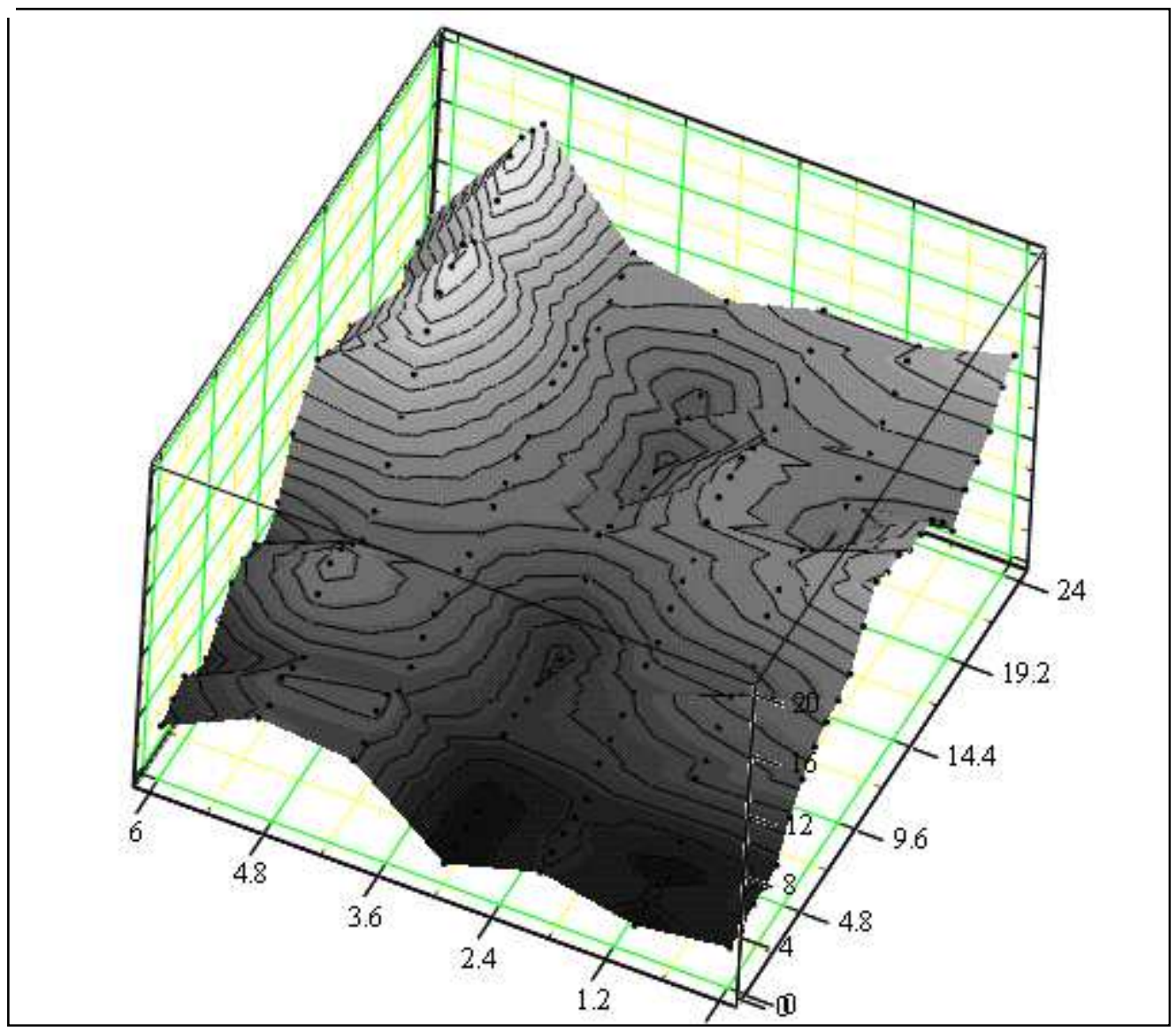

$\mathrm{u} \%, \mathrm{y} \%, \pi \%$

Figure 15. 


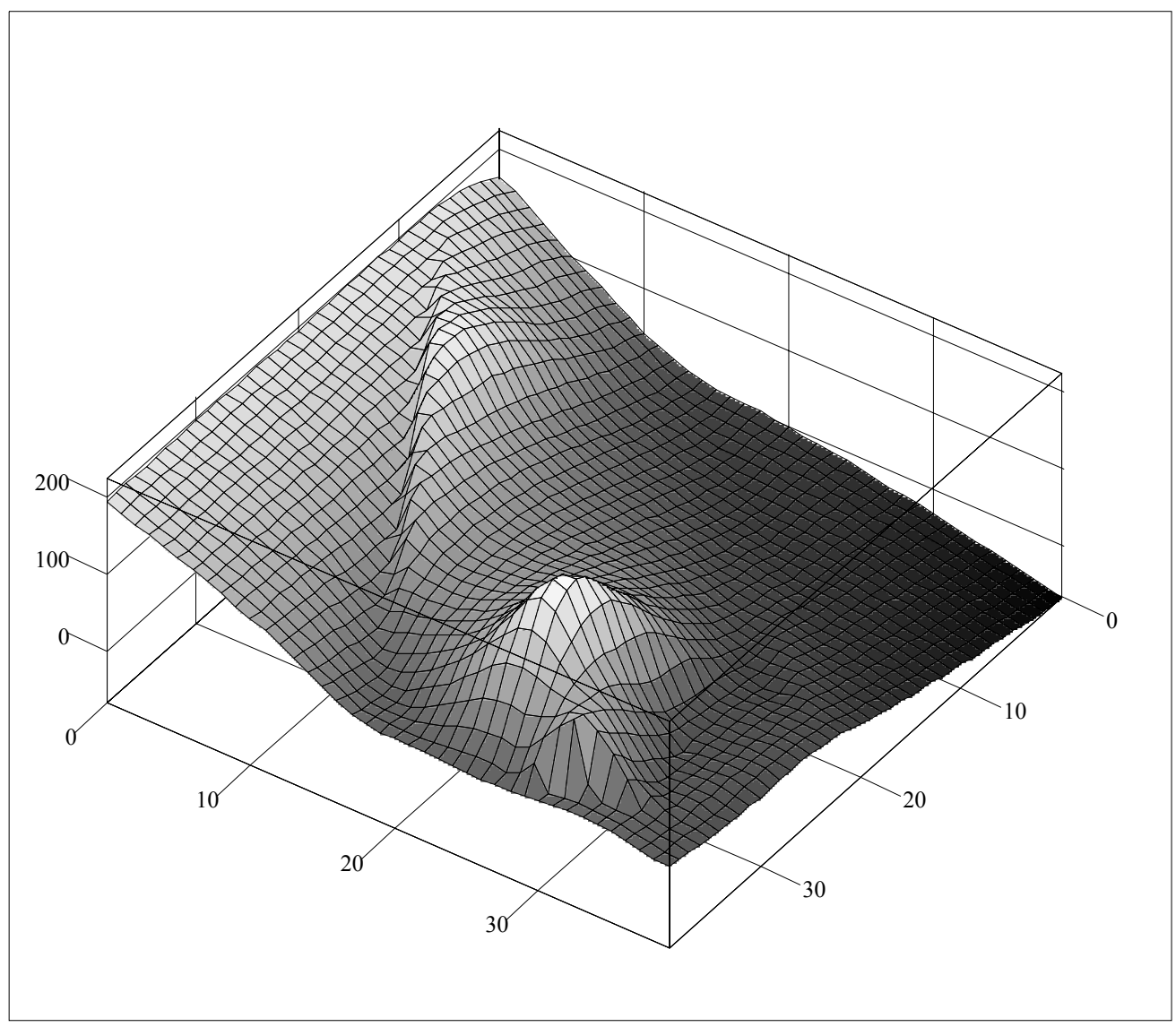

$\mathrm{u} \%, \mathrm{y} \%, \pi \%$

Figure 16.

Now, let consider the generalised variable $\mathrm{x}$ representing shares of $\mathrm{S}$ such as the model can be expressed by the following system of equations:

$\mathrm{p}(\mathrm{x})=\mathrm{x} \cdot \mathrm{S}$

$\mathrm{u}(\mathrm{x})=\mathrm{S}-\mathrm{p}(\mathrm{x})$

From this it results the following expression of PP:

$\mathrm{PP}(\mathrm{x})=\mathrm{x} \cdot(1-\mathrm{x})$

To remark that it is a continuous version of the above logistic equation. In order to investigate the behaviour of the system, let consider that the main equation of this model can be derived from a supposed existing potential function of higher degree, $\mathrm{V}(\mathrm{x} ; \mathrm{m})$ :

$\mathrm{dV} / \mathrm{dx}=0$

where $\mathrm{x}$ is the rapid variable of the system and $\mathrm{m}$ - the slow or control variable (both variables are implicitly functions of time). In our case, we chose the following potential function: 
$\mathrm{V}(\mathrm{x} ; \mathrm{m})=\left(-\mathrm{x}^{3}\right) / 3+\left(\mathrm{x}^{2}\right) / 2-\mathrm{m} \cdot \mathrm{x}$

to which it corresponds the following equation of potential surface:

$-x^{2}+x-m=0$

Comparing this with the relation of PP it results that in terms of our model the slow variable $\mathrm{m}$ can be estimated by the following expression:

$\mathrm{m}=\mathrm{P} /\left(\mathrm{S}^{2}\right)$

Considering the analysis of the graph of function $\mathrm{V}$, it results some threshold values for parameter $\mathrm{m}$. Therefore, for $\mathrm{x}$ having values among 0 and 1 , there are the following cases: a) for $0<\mathrm{m}<3 / 16, \mathrm{~V}$ has 3 real roots ( 0 and other two separated); b) for $m=3 / 16, \mathrm{~V}$ has 2 real roots ( 0 and an other double root); c) for $3 / 16<\mathrm{m}<1$, $\mathrm{V}$ has only 0 as real root. The graph of function $\mathrm{V}$ is shown in Figure 17. A very important threshold value of parameter $\mathrm{m}$ is $1 / 4$, where the maximum, minimum, and inflexion points are confounded. Other important conclusions concerning evolution and stability of the system are: there are two equilibrium curves on the potential surface - a stable equilibrium curve (C1) and an unstable equilibrium curve $(\mathrm{C} 2)$; for values of $\mathrm{x}$ smaller than $(\mathrm{C} 2)$ the trajectories are attracted to (C1) (the long-run effect); for value of $x$ greater than (C2) the system is strong attracted in an intense troubled zone; a rich menu of alternatives can be deduced by investigation of the function $\mathrm{V}$ map moreover this can offer some larger possibilities of statistical data interpretation.

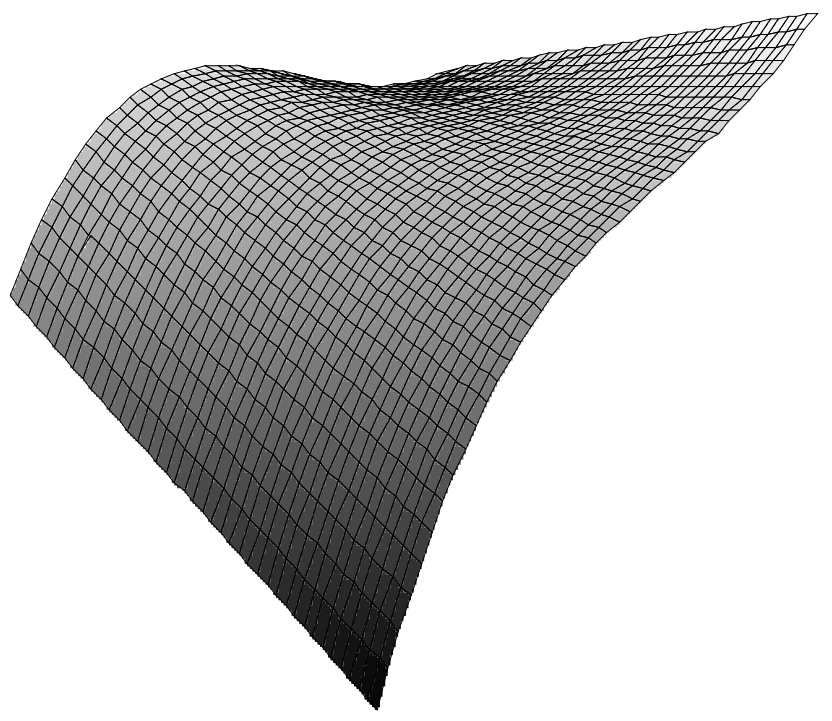

$\mathrm{M}$

Figure 17. 
Another methodology to estimate trends in economic series and to appreciate their type is that based on fractal dimension. We can choose the method called Hurst exponent. According to statistical mechanics, the Hurst exponent $(\mathrm{H})$ should equal 0.5 if the series is a random walk. In other words, the range of cumulative deviation should increase with the square root of time. When $\mathrm{H}$ differed from 0.5 , the observations were not independent. Each of these carried a "memory" of all the events that preceded it. This is not a short-term memory, which is often called Markovian. This memory is different: it is long-term. More recent events had a grater impact than distant events, but there was still residual influence. On a broader scale, a system that exhibits Hurst statistics is the result of a long stream of interconnected events. Time is very important. Inclusion of a time arrow is not possible in standard econometrics, which supposes series are invariant with respect to time (see Peters, 1991). There are three distinct intervals for the Hurst exponent: 1) $\mathrm{H}=0.50$, 2) $0<\mathrm{H}<0.50$, and 3) $0.50<\mathrm{H}<1.00$. First case denotes a random series. Events are random and uncorrelated. The present does not influence the future. Its probability density function can be normal curve. The standard statistics assume that nature follows the normal distribution, but $\mathrm{H}$ is typically greater than 0.5 for numerous series. The second type of system is an antipersistent, or ergodic, series. If the system has been up in the previous period, it is more likely to be down in the next period. In the third case we have a persistent, or trend-reinforcing, series. If the series has been up (down) in the last period, then the chances are that it will continue to be positive (negative) in the next period. The closer $\mathrm{H}$ is to 0.5 , the noisier it will be, and the less defined its trends will be. Persistent series are fractional Brownian motion, or biased random walks. The strength of the bias depends on how far $\mathrm{H}$ is above 0.50 . Persistent time series are plentiful in nature, as are probably many economic time series. Persistent time series are fractal because they can also be described as fractional brownian motion. The Hurst exponent describes the likelihood that two consecutive events are likely to occur. Because each point is not equally likely (as it is in a random walk), the fractal dimension of the probability distribution is not 2; it is a number between 1 and 2. Mandelbrot (1972) has shown that the inverse of $\mathrm{H}$ is the fractal dimension. Note that a random walk is truly 2-dimensional and would fill up a plane. For example, to estimate $\mathrm{H}$ and fractal dimension for the plan $u-p$ or for global surface (u-p-y), the following dynamic series can be used (see Daianu and Albu, 1996):

$$
\begin{aligned}
& \operatorname{doup}_{t}:=\sqrt{\left(u \%_{t}\right)^{2}+\left(p \%_{t}\right)^{2}} \\
& \text { do }_{t}:=\sqrt{\left(u \%_{t}\right)^{2}+\left(p \%_{t}\right)^{2}+\left(y \%_{t}\right)^{2}}
\end{aligned}
$$

To investigate inflation-unemployment relationship also it can be used the prototype of the pitchfork bifurcation. So, coming from the empirical data on the evolution of the unemployment in western countries in last 30-35 years and from the hypothesis on the natural rate of unemployment existing in literature, we conceived a model that can be described by the following first-order differential equation:

$\mathrm{dy} / \mathrm{dt}=\alpha[\mathrm{xn}(\mathrm{y})-\mathrm{x}(\mathrm{y})]$ 
where, $\mathrm{y}$ is the GDP per capita, $\mathrm{xn}$ - "natural" unemployment, $\mathrm{x}$ - actual unemployment, and $\alpha$ - a coefficient. Let ycr be the "natural" or "critical" level of GDP per capita, and formulate (39) in terms of the deviations from the appropriate xcr and xncr levels (we chose $\mathrm{xcr}=\mathrm{xncr})$ :

$\mathrm{dY} / \mathrm{dt}=\alpha[\mathrm{Xn}(\mathrm{y})-\mathrm{X}(\mathrm{y})]$

with $\mathrm{Y}=\mathrm{y}-\mathrm{ycr}, \mathrm{Xn}=\mathrm{xn}-\mathrm{xncr}$, and $\mathrm{X}=\mathrm{x}-\mathrm{xcr}$. Also, the following relations between $\mathrm{X}$ and $\mathrm{Y}$ and respectively between $\mathrm{Xn}$ and $\mathrm{Y}$ were initially supposed:

$\mathrm{X}(\mathrm{Y})=\mathrm{a} \mathrm{Y}+\mathrm{b}$

$\mathrm{Xn}(\mathrm{Y})=\mathrm{A} \mathrm{Y}^{3}+\mathrm{B} \mathrm{Y}^{2}+\mathrm{cY}+\mathrm{D}$

where, a, b, A, B, c, and D are coefficients. So, in points where the two curves are intersecting will be achieved the natural level of $y$. The described system seems to be like one that has behaviour of type pitchfork bifurcation. However, taking into account the condition of an odd function for $d Y / d t=f(Y ; \mu)$ with respect to $Y$, i.e., $f(Y ; \mu)=-f(-$ $\mathrm{Y} ; \mu$ ), we chose the solution $\mathrm{B}=0$, and $\mathrm{D}=\mathrm{b}$. So, the equation (42) was replaced by:

$\mathrm{Xn}(\mathrm{Y})=\mathrm{A} \mathrm{Y}^{3}+\mathrm{cY}+\mathrm{b}$

Now, after some operations, the expression of function $\mathrm{f}$ can be written as:

$\mathrm{f}(\mathrm{Y} ; \mu)=\beta\left(\mu \mathrm{Y}-\mathrm{Y}^{3}\right)$

with $\beta=-\alpha / A$ and $\mu=(a-c) / A$. Define $\mu_{0}$ as that parameter value for which the eigenvalue of (39) or in the new form of (42) is zero, i.e., $\partial \mathrm{f}\left(\mathrm{y}^{*}, \mu_{0}\right) / \partial \mathrm{y}=\lambda=0$. Then, the conditions of the existence theorem are fulfilled and a pitchfork bifurcation occurs at $\mu_{0}$ (see the existence theorems for the main types of bifurcations in Albu, 1997). We applied this model in case of some EU countries, but using three different sets of critical points and $\mu_{0}$ parameters. The main conclusion was that for greater level of GDP per capita the impacts of unemployment and respectively that of the natural unemployment on the economic growth (represented by changes in GDP) are changing in sense that the natural unemployment response to the deviation from the natural GDP level is getting smaller. Coming from a point, at a high level of GDP per capita (around 20,000 dollars/inhabitant, for example in case of Belgium), the structure of relations between unemployment and growth rate of production (GDP) changes dramatically. From that point, the dynamics of unemployment and natural unemployment became smaller and smaller related to the GDP dynamics, their evolution being more autonomous, governed by different own lows. However, the conclusion must be certificate by application on huge statistical data. Unfortunately, the achievement of one more efficient methodology still remains for future research.

To investigate inflation-unemployment relationship we used also a truncated version of the pitchfork bifurcation model, in sense that all conditions of theorem for a pitchfork are fulfilled (including that of odd function) excepting the condition referring to remaining within the unit interval [0;1] that is violated. The applications of this model in case of some countries permitted to capture several important features for medium or even long transition. So, let $\mathrm{z}(\mathrm{x})$ be the general three-order equation of inflation with respect to 
unemployment $(\mathrm{x})$, where $\mathrm{z}$ and $\mathrm{x}$ are evaluated in terms of shares within the above mentioned sum $\mathrm{S}$ :

$z(x)=a x^{3}+b a x^{2}+c x+d$

and the following three additional relations between coefficients: $d=1 ; a=2(c+2)$; and $b=-$ $3(\mathrm{c}+2)$. These relations permitted to define other function $\mathrm{z}^{*}$ as function of $\mathrm{x}$ and parameter c as follows:

$\mathrm{z}^{*}(\mathrm{x} ; \mathrm{c})=2(\mathrm{c}+2) \mathrm{x}^{3}-3(\mathrm{c}+2) \mathrm{x}^{2}+\mathrm{c} \mathrm{x}+1$

The function $\mathrm{f}$ resulting from the difference between (45) and (44), by writing $\mathrm{z}(\mathrm{x})=1-\mathrm{x}$, is as following:

$f(x ; c)=2(c+2) x^{3}-3(c+2) x^{2}+c(x+1) x=0$

It would be also viewed as a potential surface. Then, using the same procedure we write the so-called potential function from which $\mathrm{f}(\mathrm{x} ; \mathrm{c})$ is derived as follows:

$\mathrm{V}(\mathrm{x} ; \mathrm{c})=\left\{\left[(\mathrm{c}+2) \mathrm{x}^{4}\right] / 2\right\}-(\mathrm{c}+2) \mathrm{x}^{3}+\left[(\mathrm{c}+1) \mathrm{x}^{2}\right.$

The remarkable values of $\mathrm{c}$ are -4 and -2 . Thus, in fact, there are two parameters $\mathrm{c}^{*}$ and $\mathrm{c}^{* *}$ that are governing the dynamics of the system. We applied this model to the data for various EU countries. The results were too different, showing firstly if an economy is structured or not.

Other class of models useful to investigate inflation-unemployment relationship could be global bifurcations and spiral-type chaos. In connection with the Shilnikov theorem on the fulfilment of the local conditions of stability and the demonstration of presence of a homoclinical orbit, it was specified that some specific dynamical systems are known which posses a homoclinical orbit and allow the fulfilment of the local stability proprieties of the Shilnikov theorem to be easily verified (Guckenheimer and Holmes, 1983; Arneodo, Coullet, and Tresser, 1981). In a series of studies (for details see Arneodo, Coullet, and Tresser, 1981, 1982, Glendinning and Sparrow, 1984, Lorenz, 1989, and de Vilder, 1995) it was demonstrated that the following two-differentialequations dynamical system:

$\mathrm{d}^{2} \mathrm{x} / \mathrm{dt}^{2}+\mathrm{a}(\mathrm{dx} / \mathrm{dt})+\mathrm{x}=\mathrm{z}$

$\mathrm{dz} / \mathrm{dt}=\mathrm{f}_{\mu}(\mathrm{x})$,

or, written as a third-order differential equation,

$d^{3} x / d t^{3}+a\left(d^{2} x / d t^{2}\right)+d x / d t=f_{\mu}(x)$

with a as a constant, exhibit chaotic behaviour for appropriate forms of the one-parameter family of functions $f_{\mu}(x)$. For instance, the specification $f_{\mu}(x)=\mu x(1-x)$, i.e., a logistic function, like that which we used already above, yields geometrical objects that resemble the diverse Rossler attractors. The motion is characterised by a screw-type or spiral-type structure depending on the magnitude of the parameter $\mu$ (a geometrical description of the dynamical behaviour in these spiral-type attractors can be found in Berge et al., 1986). 
Other forms of the function $\mathrm{f}_{\mu}$ with similar non-invertibilities lead to comparable results (Lorenz, 1989). Here we present a very simple economic example of the emergence of a chaotic motion in three-dimensional systems analogous to the case presented above. We where inspired by the modified macroeconomic business cycle model with inventories which in its discrete-time version was first approached by Metzler (1941). Also, many improvements were coming from the Mundell's analyse within his so-called supply-side economics (1990). Our model is very closed to that studied by Gandolfo (1983) and presented by Lorenz (1989). Let y denote the GDP and assume that output adjust according to discrepancies between the natural and actual unemployment, i.e.,

$\mathrm{dY} / \mathrm{dt}=\alpha[\mathrm{Xn}(\mathrm{t})-\mathrm{X}(\mathrm{t})], \quad \alpha>0$,

with $\mathrm{Xn}(\mathrm{t})$ as the natural and $\mathrm{X}(\mathrm{t})$ as actual unemployment at $\mathrm{t}$. We suppose also that the actual unemployment changes when disequilibria prevail on the goods market, i.e., on the inflation-side

$(\mathrm{dX} / \mathrm{dt})(\mathrm{t})=\lambda[\mathrm{Z}(\mathrm{t})-\mathrm{Zn}(\mathrm{t})], \lambda>0$,

where $Z(t)$ is the actual inflation and $Z n(t)$ - the expected rate of inflation, respectively. The natural unemployment is assumed to depend linearly on the expected output, $Y^{\mathrm{e}}(\mathrm{t})$, in $\mathrm{t}$

$\mathrm{Xn}(\mathrm{t})=\mathrm{hY} \mathrm{Y}^{\mathrm{e}}(\mathrm{t}), \quad \mathrm{h}>0$,

implying that

$(\mathrm{dXn} / \mathrm{dt})(\mathrm{t})=\mathrm{h}[(\mathrm{dY} / \mathrm{dt})(\mathrm{t})]$

The expected output is determined according to a modified hypothesis of adaptive expectations which considers only the rate of change of current output but which also includes the changes in this rate:

$\mathrm{Y}^{\mathrm{e}}(\mathrm{t})=\mathrm{Y}+\mathrm{k} 1[(\mathrm{~d} \mathrm{Y} / \mathrm{dt})(\mathrm{t})]+\mathrm{k} 2\left[\left(\mathrm{~d}^{2} \mathrm{Y} / \mathrm{dt}^{2}\right)(\mathrm{t})\right]$

Thus, expected output changes according to

$\left(d Y^{\mathrm{e}} / d t\right)(t)=[(d Y / d t)(t)]+k 1\left[\left(d^{2} Y / d t^{2}\right)(t)\right]+k 2\left[\left(d^{3} Y / d t^{3}\right)(t)\right]$

Differentiating (50) with respect to time and substituting for $[(\mathrm{dXn} / \mathrm{dt})(\mathrm{t})]$ and

$[(\mathrm{dX} / \mathrm{dt})$

(t)] yields the third-order differential equation

$\left[\left(\mathrm{d}^{3} \mathrm{Y} / \mathrm{dt}^{3}\right)(\mathrm{t})\right]+[(\alpha \mathrm{hk} 1-1) /(\alpha \mathrm{hk} 2)]\left[\left(\mathrm{d}^{2} \mathrm{Y} / \mathrm{dt}^{2}\right)(\mathrm{t})\right]+(1 / \mathrm{k} 2)[(\mathrm{dY} / \mathrm{dt})(\mathrm{t})]=$
$=[\lambda /(\mathrm{a} \mathrm{k} 2)][\mathrm{Z}(\mathrm{t})-\mathrm{Zn}(\mathrm{t})]$

or, abbreviated,

$\left[\left(\mathrm{d}^{3} \mathrm{Y} / \mathrm{dt}^{3}\right)(\mathrm{t})\right]+\mathrm{K} 1\left[\left(\mathrm{~d}^{2} \mathrm{Y} / \mathrm{dt}^{2}\right)(\mathrm{t})\right]+\mathrm{K} 2[(\mathrm{dY} / \mathrm{dt})(\mathrm{t})]=\beta[\mathrm{Z}(\mathrm{t})-\mathrm{Zn}(\mathrm{t})]$

with $\beta=\lambda /(\mathrm{ak} 2)$. Gandolfo (1983) demonstrated that a equation like (57) is unstable when $Z(t)$ is a linear function of output, e.g., in our case, $Z(t)=(1-c) Y(t)-Z 0,1 \geq c>0$, when $Z n$ is autonomous, i.e., $\mathrm{Zn}(\mathrm{t})=\mathrm{Zn} 0, \mathrm{Zn} 0>0$, and when $\mathrm{K} 1<0$. The linearity of the inflation rate 
and expected inflation functions is assumed only for technical convenience. However, there is no convincing reason why these linear functions should constitute the only economically relevant forms. Once the linearity assumption is abandoned, it can be shown that the modified model has the form (49) with a noninvertible function $f_{\mu}\left({ }^{\prime}\right)$. Define $\mathrm{y}^{*}, \mathrm{zn}^{*}, \mathrm{z}^{*}, \mathrm{x}^{*}$, and $\mathrm{xn}^{*}$ as the equilibrium values of output, expected and actual inflation rate, unemployment and natural unemployment, respectively, and consider the deviation from these equilibrium values, i.e., $y=Y-y^{*}, z n=Z n-z^{*}, z=Z-z^{*}, x=X-x^{*}$, and $\mathrm{xn}=\mathrm{Xn}-\mathrm{xn}^{*}$. Equation (57) then becomes

$\left[\left(d^{3} y / d t^{3}\right)(t)\right]+K 1\left[\left(d^{2} y / d t^{2}\right)(t)\right]+K 2[(d y / d t)(t)]=\beta[z(t)-z n(t)]$

Assume that both actual and expected inflation are nonlinear function of output. Possible shapes of the functions that exhibit two points of intersection of the actual inflation and expected inflation can be supposed. The difference $\mathrm{z}(\mathrm{y})-\mathrm{zn}(\mathrm{y})$ therefore describes a onehumped curve similar to the logistic function $\mathrm{f}_{\mu}(\mathrm{x})=\mu \mathrm{x}(\mathrm{d}-\mathrm{x})$, used by Ameodo et al. (1981) for the case $\mathrm{d}=1$.

Assumption: (i) $\mathrm{K} 1>0$ and $\mathrm{K} 2$ close to unity; (ii) $\beta\left[\mathrm{z}_{\mu}\right.$ (y) $-\mathrm{zn}_{\mu}$ (y)] is one-humped function $f_{\mu}(y)$ with a critical value $y_{c r}>0$, the slope of which can be controlled by a single parameter $\mu$. Under this assumption, our model (58), also being similar to the Metzlerian model, is nearly identical with equation (49). The Lie derivative (the divergence) of (58) is negative because of $\mathrm{K} 1>0$ (the calculated Lyapunov exponents for similar models, when the parameters are adequate selected yields a positive and a negative exponent in addition to the zero exponent; see Lorentz, 1989 for details). The system is therefore volume contracting and possesses an attracting invariant set. The dynamic behaviour of (58) is not essentially different from that of (49) and it can see that (58) possesses a Shilnikov-type structure for the assumed values of $\mathrm{K} 1, \beta$, and the slope of the excess supply function. In contrast to logistic, one-dimensional difference equations, rather flat shapes of the one-humped curve are sufficient to encounter chaotic motion (Arneodo et al., 1982). It can be expected that several other modifications of the model are possible which still imply the emergence of a Shilnikov-type attractor when the excess supply function is noninvertible. The main remaining problem, including for our future research, is how we should capture these types of attractors from the actual set of existing statistical data.

We used also a discrete-time nonlinear model to investigate transitions to chaos in a modified Phillips curve system. The stagflation phenomenon was relatively recent added to the problematic of inflation-unemployment relationship (Santeremo and Seater, 1978). Also, we mention that early empirical investigations indicated an inverse nonlinear relationship (Phillips, 1958; Lipsey, 1960). An attempt to model the stagflation phenomenon has included through introduction of some additional factors in explaining actual inflation, such as the expected inflation rate (Friedman, 1968). One more complete approach to model the stagflation is provided by Fischer and Jammernegg (1986) who conceived a dynamical system based on the catastrophe theory approach (Lorentz, 1989). Among studies that incorporated the Phillips curve we mention here those of Goodwin (1967), Pohjola (1981), and Soliman (1996). Our model consists in the following system of three equations: 


$$
\left[\begin{array}{c}
\pi_{t} \\
\pi e_{t+1} \\
u_{t+1}
\end{array}\right]:=\left[\begin{array}{c}
g\left(u_{t}\right)+h 1 \cdot \pi e_{t} \\
\pi e_{t}+h 2 \cdot\left(\pi_{t}-\pi e_{t}\right) \\
-h 3 \cdot\left(\pi e_{t+1}-\pi_{t}\right)+u_{t}
\end{array}\right]
$$

where $\pi_{\mathrm{t}}$ and $\pi \mathrm{e}_{\mathrm{t}}$ are the actual inflation and expected inflation rates in period $\mathrm{t}$ respectively and $\mathrm{u}_{\mathrm{t}}$ is the level of unemployment in period t. The incorporation of inflationary expectations into actual inflation is represented by the parameter $\mathrm{h} 1$ $(0 \leq \mathrm{h} 1 \leq 1)$. The second equation expresses the fact that the inflationary expectations are adaptive expectations. The parameter $\mathrm{h} 2(0 \leq \mathrm{h} 2 \leq 1)$ represents the degree that errors made in predicting actual inflation are corrected. The unemployment dynamics is expressed by the last equation of system, which includes the assumption that the next unemployment rate will be influenced by the difference between expected inflation and actual inflation. The extent of this influence is governed by the elasticity of unemployment with respect to real monetary growth, therefore parameter $h 3 \quad(h 3>0)$. Although there is theoretical justification for non-linear inflation-unemployment relationship in literature, there is no agreement with respect to its functional form. In our model we considered the following functional form:

$\mathrm{g}(\mathrm{u}):=\left(\frac{\mathrm{k} 1}{\mathrm{lcr}^{2}}+\mathrm{k} 2\right) \cdot(1-\mathrm{u})^{2}+\left(-\frac{\mathrm{k} 3}{\mathrm{lcr}}-\mathrm{k} 4\right) \cdot(1-\mathrm{u})+\mathrm{k} 5$

where $\mathrm{k} 1, \mathrm{k} 2, \mathrm{k} 3, \mathrm{k} 4, \mathrm{k} 5$, and lcr are parameters. We mention that this functional form represents the result of other model that we used to estimate a critical level of unemployment, ucr (ucr=1-lcr), under the condition of a Cobb-Douglas production function with respect to the employment level. The simulations based on the model demonstrate a very complex dynamics of inflation-unemployment relationship and the existence of attractors in case of some critical values of parameters as well. Also, the large sensibility to the small differences in the initial values is evident. In Figure 18 are presented several functioning regimes in the $\left(\pi_{t}-u_{t-1}\right)$-space varying with two sets of data attributed to parameters, but many others regimes can be extracted from the model simulation. The values of fixed parameters are $\mathrm{lcr}=0.71 ; \mathrm{k} 1=3 ; \mathrm{k} 2=0.8 ; \mathrm{k} 3=6$; and $\mathrm{k} 4=4$. As initial set of values for $\pi$, $\mathrm{u}$, and $\pi \mathrm{e}$, we chose $\pi 0=0.08, \mathrm{u} 0=0.09$, and respectively $\pi \mathrm{e}=$ 0.08 . The parameters that change are h1 $(0.1 ; 0.2 ; 0.3 ; 0.5), \mathrm{h} 2(0.1 ; 0.3 ; 0.45)$, and $\mathrm{h} 3$ $(0.6 ; 0.5 ; 0.7 ; 0.9)$. 

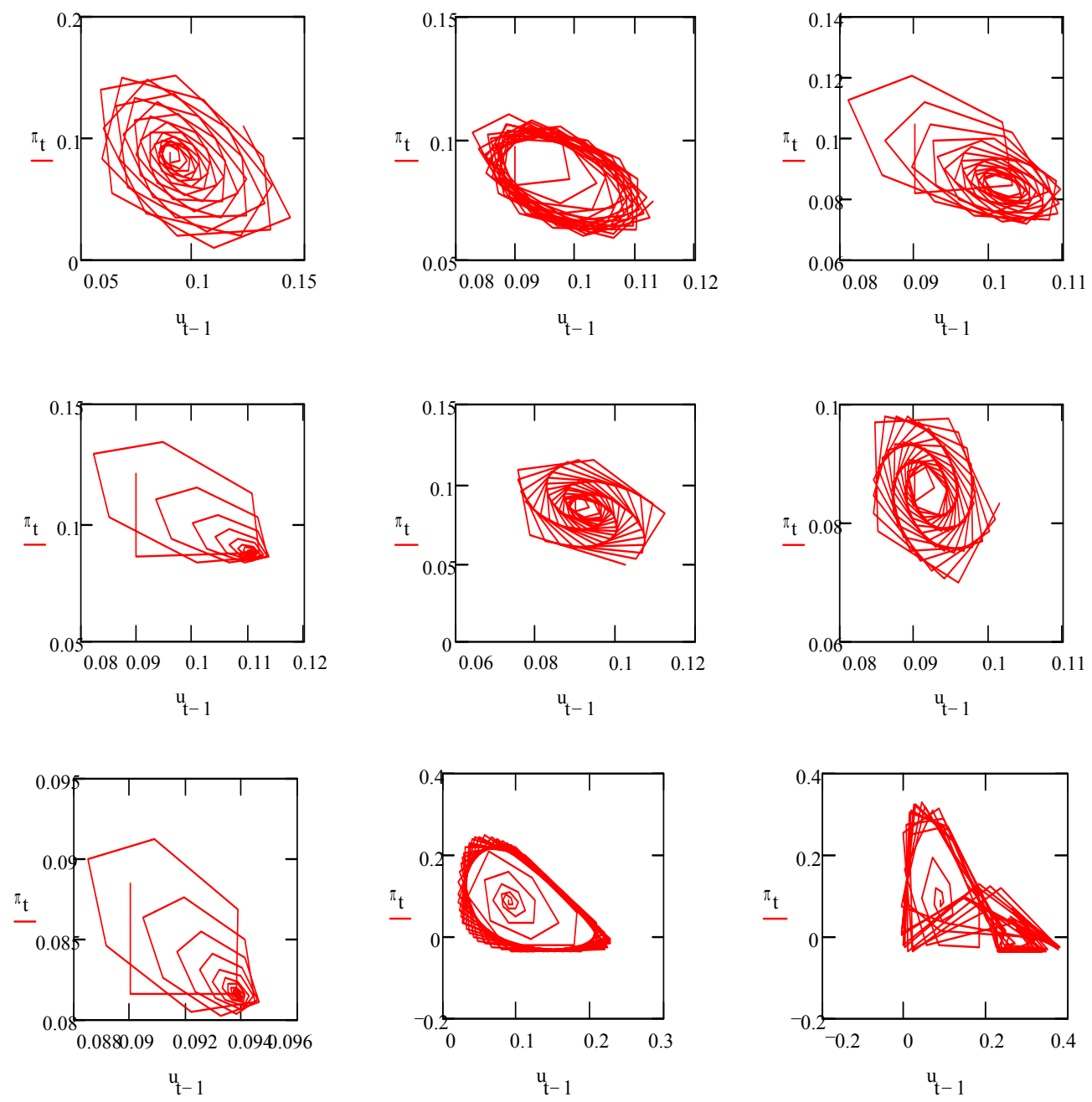

Figure 18. 


\section{Selected Bibliography}

Albu, L.-L. (1995): La modélisation de l'économie souterraine et des politiques fiscales, CEPREMAP - Paris, ACE - PHARE, August.

Albu, L.-L. (1996): “Teoria discontinuităţilor şi aplicaţii în economie" (Theory of Discontinuities and Applications in Economics), Oeconomica, 2, SOREC, IRLI, Bucharest.

Albu, L.-L. (1997): Strain and inflation-unemployment relationship in transitional economies: a theoretical and empirical investigation, University of Leicester, Department of Economics, Centre for Economic Studies, Leicester, ACE-PHARE, December.

Albu, L.-L. (1998): Tranziția economiei sau tranziția ştiinței economice? (Transition of Economy or Transition of Economics?), Expert, Bucharest.

Albu, L.-L. (2002): Macroeconomie non-lineară şi prognoză - teorie şi aplicație (NonLinear Macroeconomics and Forecast - Theory and Aplications), Expert, Bucharest.

Ameodo, A., Coullet, P., and Tresser, C. (1981): "Possible New Strange Attractors with Spiral Structure", Communications in Mathematical Physics 79.

Ameodo, A., Coullet, P., and Tresser, C. (1982): "Oscillations with Chaotical Behavior: An Ilustration of a Theorem by Shilnikov", Journal of Statistics Physics 27.

Arthur, B. (1988): "Self-reinforcing Mechanism in Economics", in Anderson, P.K. Arrow and D. Pines (eds.): The Economy as an Evolving Complex System, AddisonWesley, Reading, MA.

Benhabib, J. (1992): Chaos and Cycles in Economic Equilibrium, Princeton University Press, Princeton.

Berge, P., Pomeau, Y., and Vidal, C. (1986): Order within Chaos. New York: Wiley.

Black, F. (1982): "General Equilibrium and Business Cycles", NBER Working Paper, 950.

Blanchard, O.J. and Fischer S. (1993): Lectures on Macroeconomics, MIT Press, Cambridge, MA.

Blatt, J.M. (1978): "On the Econometric Approach to Business-Cycle Analysis", Oxford Economic Papers, 30.

Brock, W.A. (1986): "Distinguishing Random and Deterministic Systems", Journal of Economic Theory, 40.

Brock, W.A. (1992): Pathways to Randomness in the Economy: Emergent Nonlinearity and Chaos in Economics and Finance, University of Wisconsin.

Brock, W.A., Hsie, D.A., and LeBaron, B. (1991): Nonlinear Dynamics, Chaos and Instability, MIT Press, Cambridge, MA.

Burns, A. (1969): "The Business Cycle in a Changing World", National Bureau of Economic Research, New York.

Burns, A. and Mitchell, W. (1946): "Measuring Business Cycles", National Bureau of Economic Research, New York.

Day, R.H. (1982): 'Irregular Growth Cycles", American Economic Review, 72 (3).

Daianu, D. and Albu, L.-L. (1996): Strain and the Inflation-Unemployment Relationship: A Conceptual and Empirical Investigation. Econometric Inference into the Macroeconomic Dynamics East European Economies, University of Leicester, UK. Research Memorandum, No. 96/15. 
Feigenbaum, M. (1978): "Quantitative Universality for a Class of non-linear Transformations", Journal of Statistical Physics, 19.

Fischer, E.O. and Jammernegg, W. (1986): "Empirical Investigation of a Catastrophe Extension of the Phillips-curve", Review of Economics and Statistics.

Friedman, M. (1968): “The Role of Monetary Policy”, American Economic Review 58.

Friedman, M. and Schwartz, A.J. (1963): A monetary History of the United States, 1867-1960, Princeton University Press.

Gandolfo, G. (1983): Economic Dynamics: Methods and Models. 2nd ed., Amsterdam: North-Holland.

Gilmore, R. (1981): Catastrophe Theory for Scientists and Engineers, John Wiley, New York.

Glendinning, P. and Sparrow, C. (1984): "Local and Global Behavior near Homoclinic Orbits", Journal of Statistical Physics 35.

Goodwin, R.M. (1951): "The Nonlinear Acceleration and the Persistance of Business Cycles", Econometrica, 19 (1).

Goodwin, R.M. (1967): "A Growth Cycle". Socialism, Capitalism and Economic Growth. C.H. Feinstein (ed.). Cambridge University Press.

Graham, A. and Senge, P. (1980): "A Long Wave Hypothesis of Innovation", Technological Forecasting and Social Change, 17.

Grandmont, J.M. (1988): Nonlinear Economic Dynamics, Academic Press, Boston.

Granger, C.W.J. şi Terasvirta, T. (1993), Modelling Nonlinear Economic Relationships, Oxford University Press, Oxford.

Guckenheimer, J. and Holmes, P. (1983): Nonlinear Oscillations, Dynamical Systems, and Bifurcations of Vector Field, Springer Verlag, Berlin-Heidelberg.

Henon, M. (1976): "A Two Dimensional Mapping with a Strange Attractor", Communications in Mathematical Physics, 50.

Hermann, R. (1985): "Stability and Chaos in a Kaldor-type Model", Department of Economics, University of Gottingen, Discussion Paper No. 22.

Klein, L.R. şi Preston, R.S. (1969): "Stochastic Nonlinear Models", Econometrica, 37.

Li, T.Y. and Yorke, J.A. (1975): "Period Three Implies Chaos", American Mathematical Monthly, 82.

Lipsey, R.G (1960): "The Relation between Unemployment and the Rate of Change of Money Wage Rates in the United Kingdom, 1862-1957: A Further Analysis", Economica 27.

Lorenz, E.N. (1963): "Deterministic Non-period Flows", Journal of Atmospheric Sciences, 20.

Lorenz, H-W. (1989): Nonlinear Dynamical Economics and Chaotic Motion, Lecture Notes in Economic and Mathematical Systems 334, Springer Verlag, Berlin.

Mandelbrot, B. (1972): "Statistical Methodology for Non-Periodic Cycles: From the Covariance to R/S Analysis", Annals of Economic and Social Measurement 1.

Marotto, F.R. (1978): "Snap-back Repellors Imply Chaos in $\mathrm{R}^{\mathrm{n}}$ ", Journal of Mathematical Analzsis and Applications, 72.

May, R.M. (1976): "Simple Mathematical Models With Very Complicated Dynamics", Nature 261.

Metzler, L.A. (1941): "The Nature and Stability of Inventory Cycles", Review of Economic Studies 23. 
Mitchell, W.C. (1927): "Business Cycles: The Problem and Its Setting", National Bureau of Economic Research, New York.

Mundell, R.A. (1990): "Debts and Deficits in Alternative Macroeconomic Models", Revista di Politica Economica, VII-VIII, Roma.

Nelson, C. and Plosser, C. (1982): "Trends and Random Walks in Macroeconomic Time Series", Journal of Monetary Economics 10.

Okun, A.M. (1962): "Potential GNP: Its Measurement and Significance", Reprinted in J. Pechman (ed.), Economics for Policymaking, MIT Press, Cambridge, MA, 1983.

Phillips, A.W. (1958): “The Relation between Unemployment and the Rate of Change of Money Wage Rates in the United Kingdom, 1861-1957”, Economica 25.

Pohjola, M.T. (1981): "Stable, Cyclic and Chaotic Growth: the Dynamics of a Discrete Time Version of Goodwin's Growth Cycle Model", Zeitschrift fur Nationalekonomie 41.

Ramsey, J.B. (1988): "Economic and Financial Data as Nonlinear Processes", in G.P. Dwyer şi R.W. Hafer (eds.), The Stoc Market: Bubbles, Volatility, and Chaos, Kluwer Academic Publishers, Boston.

Reichlin, P. (1997): "Endogenous Cycles in Competitive Models: An Overview", Studies in Nonlinear Dynamics and Econometrics Quarterly Journal, Volume 1, Number 4, The MIT Press, January.

Rossler, O.E. (1976): "An Equation for Continous Chaos", Physics Letters, 57A.

Ruelle, D. (1979): "Repellers for Real Analytic Maps", Ergodic Theory and Dynamic Systems, 2.

Ruelle, D. and Takens, F. (1971): "On the Nature of Turbulence", Communications in Mathematical Physics, 20.

Santeremo, A.M. and Seater, J.L. (1978): "The Inflation Unemployment Trade-Off: A Critique of the Literature", Journal of Economic Literature 16.

Soliman, A.S. (1996): "Transition from Stable Equilibrium Points to Periodic Cycles to Chaos in a Phillips Curve System", Journal of Macroeconomics, 18.

Tong, H. (1990): Nonlinear Time Series. A Dynamical System Approach, Oxford University Press, Oxford.

Vilder, R.G. (1995): Endogenous Business Cycles, Tinbergen Institute Research Series, 96.

Woodcock, A.E.R. and Davis, M. (1979): Catastrophe Theory. London: Penguin.

Zarnowitz, V. (1985): "Recent Work on Business Cycles in Historical Perspective: A Review of Theories and evidence", Journal of Economic Literature, 23. 